Article

\title{
Synthesis of Key Fragments of Amphidinolide Q - A Cytotoxic 12-membered Macrolide
}

\author{
Kohei Kawa, Akihiro Hara, Yuichi Ishikawa and Shigeru Nishiyama * \\ Department of Chemistry, Faculty of Science and Technology, Keio University, Hiyoshi 3-14-1, \\ Kohoku-ku, Yokohama 223-8522, Japan
}

* Author to whom correspondence should be addressed; E-Mail: nisiyama@chem.keio.ac.jp; Tel.: +81 455631717, Fax: +81 455661717.

Received: 31 May 2011; in revised form: 20 June 2011 / Accepted: 22 June 2011 /

Published: 27 June 2011

\begin{abstract}
Hydroxy aldehyde and alkyl ketone moieties were effectively synthesized as key intermediates of amphidinolide Q, a cytotoxic macrolide from the cultured dinoflagellate Amphidinium sp.. The asymmetric center of the former derivative was produced by Sharpless asymmetric epoxidation, followed by $E$-selective 1,4-addition to give the $\mathrm{sp}^{2}$ methyl group. Derivatization of the L-ascorbic acid derivative by Evans asymmetric alkylation and Peterson olefination provided the latter intermediate. The coupling reaction of the segments was examined.
\end{abstract}

Keywords: amphidinolide Q; Amphidinium sp.; macrolide synthesis; cytotoxic marine natural product

\section{Introduction}

Amphidinolide Q (1, Scheme 1) is a member of the cytotoxic macrolide family isolated from the cultured dinoflagellate Amphidinium sp., and its absolute stereostructure was chemically determined by Kobayashi and co-workers [1,2]. This macrolide exhibits potent cytotoxicity against L1210 murine leukemia cells. Due to its low natural abundance, the detailed structure-activity relationship of $\mathbf{1}$ has not been established. Although 1 was synthesized by Kobayashi's group in 2009 [3], further increases in synthetic efficiency and examination of related substances based on new synthetic approaches are 
required to explain the detailed mode of action of $\mathbf{1}$ by structure-activity relationship studies, and to develop new bioactive substances superior to the mother macrolide. We describe herein an efficient method for synthesis of segments 2 and 3, which will be important intermediates for the construction of 1.

\section{Results and Discussion}

As outlined in Scheme 1, retrosynthetic analysis showed that amphidinolide Q (1) could be obtained by successive coupling of $\mathbf{2}$ and 3, with the former, carrying a stereogenic center and a tri-substituted olefin, being produced from the known allyl alcohol 4 through $E$-selective 1,4-addition of a methyl group at $\mathrm{C} 3$ and Sharpless asymmetric epoxidation. The alkyl ketone 3 carrying three stereogenic centers could be obtained from the ascorbic acid derivative 5 through Evans asymmetric alkylation.

Scheme 1. Amphidinolide Q (1) and retrosynthetic analysis.

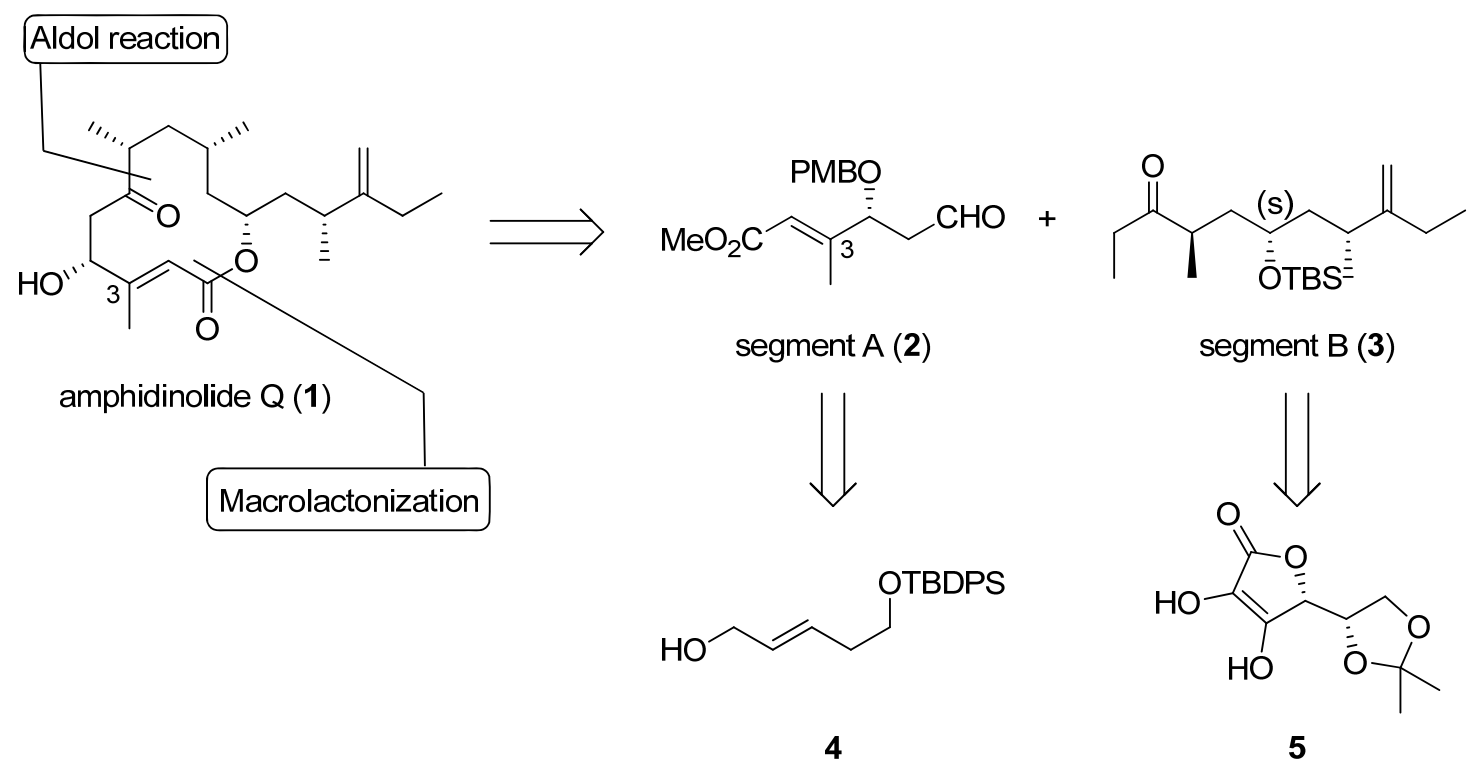

\subsection{Synthesis of segment $A$ (2)}

The synthesis of 2 commenced with the conversion of 1,3-propanediol (6) into alcohol 4 (Scheme 2) [4]. Incorporation of the asymmetric center at $\mathrm{C} 4$ and carbon chain elongation were carried out by Sharpless asymmetric epoxidation, followed by chlorination, alkynylation [5], and final $p$-methoxybenzyl (PMB) protection of the newly produced $\mathrm{OH}$ group under acidic conditions to avoid unexpected removal of the tert-butyldiphenylsilyl (TBDPS) group. Further manipulation of 7 involved introduction of a methoxycarbonyl group at the terminal of the alkynyl carbon to give 8, which upon $E$-selective alkylation using a $\mathrm{PhS}$ group as an auxiliary [6], afforded the $\alpha, \beta$-unsaturated ester 9. In this case, the two-step procedure involving preparation of the vinyl sulfide, followed by exchange with a methyl group must be used to afford the $\alpha, \beta$-unsaturated ester 9 in good yield (Table 1). In the case of direct methylation (path A), the desired compound 9 was obtained in low yield, even when the reaction temperature was increased to $0{ }^{\circ} \mathrm{C}$ (entry 2). Although a number of reagent combinations to 
control the properties of cuprates are known, the desired product was obtained in good yield in the case of entry 5.

Deprotection and oxidation processes ultimately gave the $\beta$-hydroxyl aldehyde 2 (segment A) in good overall yield.

Scheme 2. Synthesis of segment A (2).

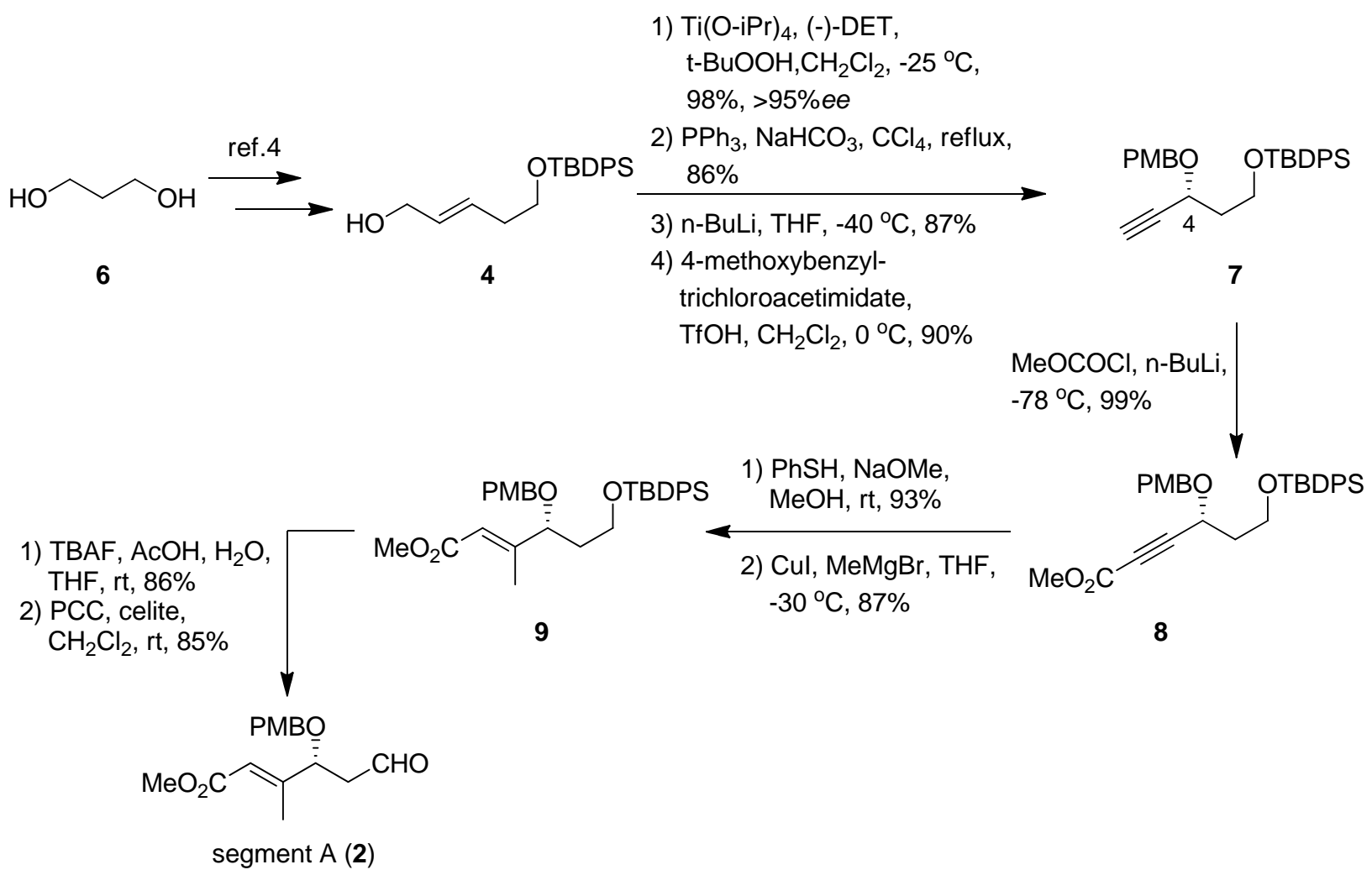

Table 1. 1,4-Addition of methyl group at C3 position of compound 6.

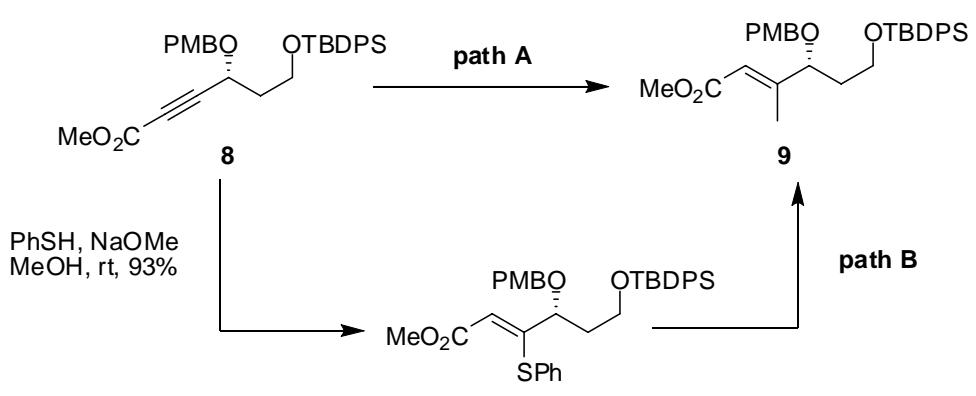

\begin{tabular}{cccccccc}
\hline entry & path & $\begin{array}{c}\text { Cu reagent } \\
(20 \text { eq. })\end{array}$ & $\begin{array}{c}\text { alkylating agent } \\
\text { (39 eq. })\end{array}$ & solvent & $\begin{array}{c}\text { reaction } \\
\text { temperature }\end{array}$ & $\mathbf{9}$ & $\mathbf{8}$ \\
\hline 1 & $\mathrm{~A}$ & $\mathrm{CuCN}$ & $\mathrm{MeLi}$ & $\mathrm{Et}_{2} \mathrm{O}$ & $-30{ }^{\circ} \mathrm{C}$ & $18 \%$ & - \\
2 & $\mathrm{CuCN}$ & $\mathrm{MeLi}$ & $\mathrm{Et}_{2} \mathrm{O}$ & $0{ }^{\circ} \mathrm{C}$ & $32 \%$ & - \\
\hline 3 & $\mathrm{~B}$ & $\mathrm{CuCN}$ & $\mathrm{MeLi}$ & $\mathrm{Et}_{2} \mathrm{O}$ & $-30{ }^{\circ} \mathrm{C}$ & - & $100 \%$ \\
4 & $\mathrm{Cul}$ & $\mathrm{MeLi}$ & $\mathrm{Et}_{2} \mathrm{O}$ & $-30{ }^{\circ} \mathrm{C}$ & - & $71 \%$ \\
\hline 5 & $\mathrm{Cul}$ & $\mathrm{MeMgBr}$ & $\mathrm{THF}$ & $-30{ }^{\circ} \mathrm{C}$ & $87 \%$ & - \\
\hline 6 & $\mathrm{Cul}$ & $\mathrm{MeMgBr}$ & $\mathrm{THF}$ & $-78{ }^{\circ} \mathrm{C}$ & $33 \%$ & $52 \%$ \\
\hline
\end{tabular}




\subsection{Synthesis of segment B (3)}

Synthesis of alkyl ketone 3 was initiated by transformation of the ascorbic acid derivative 5 into diol 10 by a known procedure [7] (Scheme 3).

Scheme 3. Synthesis of segment B (3).<smiles>CC1(C)OC[C@H]([C@H]2OC(=O)C(O)=C2O)O1</smiles>

5

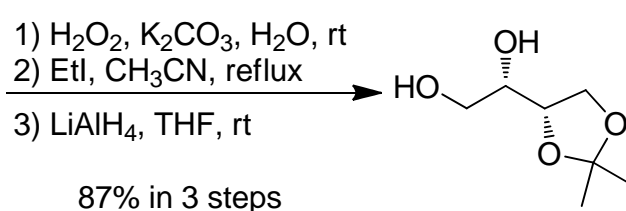

10
1) $\mathrm{NaIO}_{4}, \mathrm{CH}_{2} \mathrm{Cl}_{2} / \mathrm{H}_{2} \mathrm{O}$, rt, then $\mathrm{Ph}_{3} \mathrm{PCHCO}_{2} \mathrm{Me}$, rt

3) $\mathrm{LiOH}, \mathrm{THF} / \mathrm{H}_{2} \mathrm{O}, \mathrm{O}^{\circ} \mathrm{C}$

$82 \%$ in 3 steps

11

1) (R)-4-Benzyl-2-oxazolidinone $\mathrm{Et}_{3} \mathrm{~N}, \mathrm{PivCl}, \mathrm{LiCl}, \mathrm{rt}, 100 \%$

2) LHMDS, Mel, THF, -40 to $-20{ }^{\circ} \mathrm{C}, 90 \%$

\author{
1) PivCl, $\mathrm{CH}_{2} \mathrm{Cl}_{2}$, \\ pyr., rt, $98 \%$ \\ 2) $\mathrm{TBSCl}, \mathrm{DMF}$, \\ imidazole, $\mathrm{rt}$ \\ 3) DIBAL, $\mathrm{CH}_{2} \mathrm{Cl}_{2}$, \\ $-78^{\circ} \mathrm{C}$ \\ $97 \%$ in 2 steps<smiles>CC(COCc1ccccc1)CC(CO)CO[SbH2]</smiles>
14

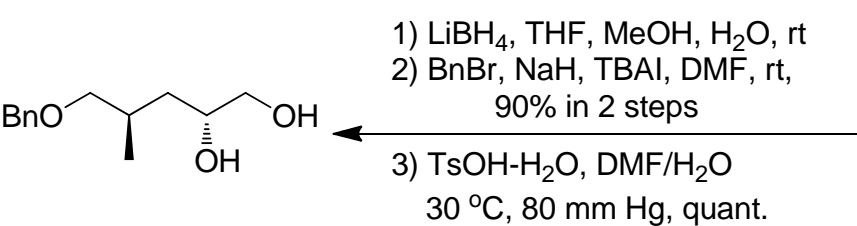

13<smiles>CC(CC1COC(C)(C)O1)C(=O)N1C(=O)OCC1Br</smiles>

12

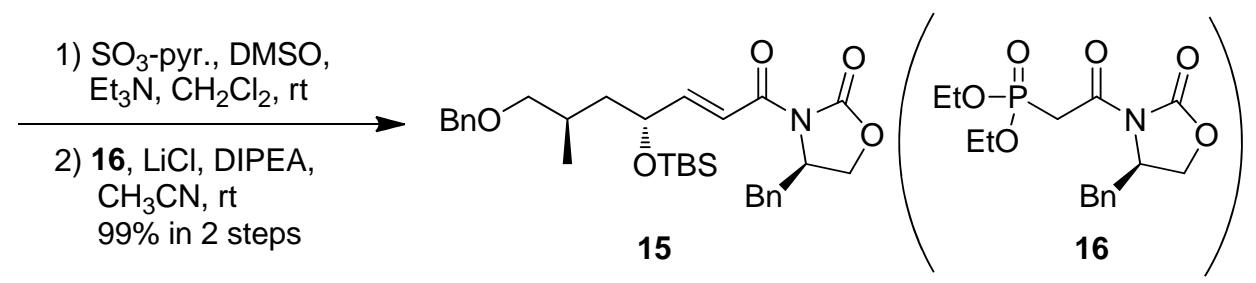<smiles>CCC(=O)[C@@H](CC)C[C@@H]([SeH])CC(C)COCc1ccccc1</smiles>

18
1) $\mathrm{LiBH}_{4}, \mathrm{THF}$, $\mathrm{MeOH}, \mathrm{H}_{2} \mathrm{O}, \mathrm{rt}, 93 \%$

2) $\mathrm{SO}_{3}$-pyr., DMSO, $\mathrm{Et}_{3} \mathrm{~N}, \mathrm{CH}_{2} \mathrm{Cl}_{2}$, rt

3) $\mathrm{EtMgBr}, \mathrm{THF}, 0^{\circ} \mathrm{C}$, $89 \%$ in 2 steps

4) $\mathrm{SO}_{3}$-pyr., DMSO, $\mathrm{Et}_{3} \mathrm{~N}, \mathrm{CH}_{2} \mathrm{Cl}_{2}$, rt, quant

1) $\mathrm{TMSCH}_{2} \mathrm{Li}, \mathrm{THF}$, $-78^{\circ} \mathrm{C}, 88 \%$

2) $\mathrm{NaH}, \mathrm{THF}$, reflux, 98\%;<smiles>C=C(CC)C(CC)CC(C)(CC(C)COCc1ccccc1)[Se]O</smiles>

19
1) $\mathrm{H}_{2}, \mathrm{Rh}-\mathrm{Al}_{2} \mathrm{O}_{3}$, EtOAc, rt, $96 \%$

2) LHMDS, $-40^{\circ} \mathrm{C}$, then Mel, $-20{ }^{\circ} \mathrm{C}, \mathrm{THF}, 77 \%$

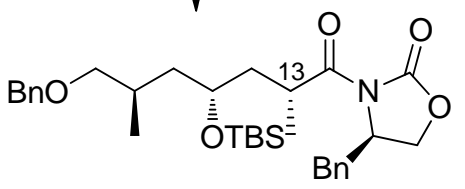

17

Compound $\mathbf{1 0}$ was subjected to oxidative cleavage of the vicinal diol, followed by immediate Wittig reaction, hydrogenation, and hydrolysis to give 11. In particular, the second Wittig reaction was carried out using crude aldehyde to avoid undesired epimerization of the asymmetric center at C11. 
Selective asymmetric induction at C9 by the Evans protocol effected the desired introduction of a methyl group to yield 12. Removal of the chiral auxiliary by $\mathrm{LiBH}_{4}$ and manipulation of protecting groups in five steps gave the alcohol 14 via 13. After Parikh-Doering oxidation of 14, the aldehyde generated was reacted with Horner-Wadsworth-Emmons reagent 16 [8] to yield 15, which on hydrogenation followed by addition of a methyl group produced 17. After removal of the auxiliary by $\mathrm{LiBH}_{4}$, an ethyl ketone function was constructed (compound 18), and the exo-methylene function was introduced by Peterson olefination, followed by basic treatment, whereas other methods, such as the Wittig and Petasis reactions did not produce the desired compound, probably due to the low reactivity of the ethylketone moiety. Synthesis of segment B (3) was accomplished by Birch reduction, followed by alkylation similar to that described the case of $\mathbf{1 8}$ and Parikh-Doering oxidation and Grignard reaction.

The synthetic strategies used for both segments may enable the synthesis of analogs. The stereogenic centers were introduced via asymmetric reactions, which can produce another enantiomer by exchanging the auxiliary group or catalyst, with the exception of the $\mathrm{C} 11$ center: in this case the opposite $(R)$-enantiomer would be produced using $(R)$-glyceraldehyde acetonide, derived from D-mannitol [9].

Aldol coupling of both segments was attempted, as shown in Scheme 4. Whereas Lewis acidic conditions such as method B [10] caused undesirable elimination of 2 and 20 [11] to give the corresponding $\alpha, \beta, \delta, \gamma$-unsaturated ester, basic conditions (method A) provided 20, equipped with the complete carbon framework, in moderate yield,. Detailed studies of the diastereomer distribution to improve the coupling yields are currently in progress in our laboratory.

Scheme 4. Coupling attempts between 2 and 3 [12].

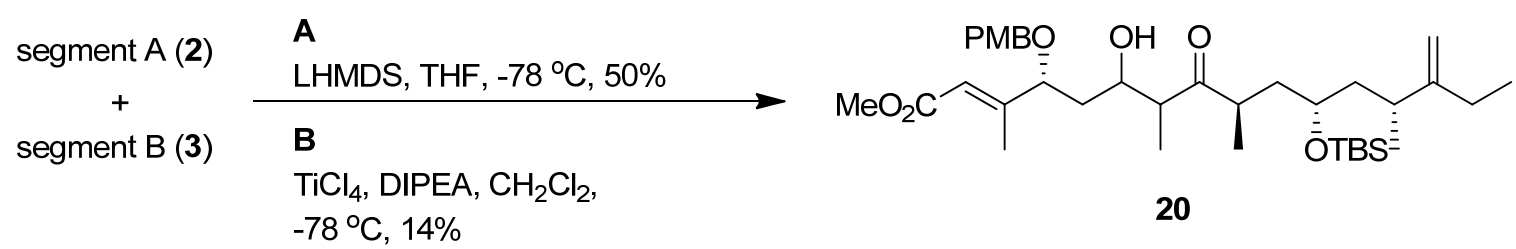

\section{Experimental}

\section{General}

All reactions were carried out under an argon atmosphere unless otherwise noted. When necessary, solvents were dried prior to use. Dry THF, dry $\mathrm{Et}_{2} \mathrm{O}$ and dry $\mathrm{CH}_{2} \mathrm{Cl}_{2}$ were purchased from Kanto Chemical Co., Inc. Optical rotations were measured on a JASCO P-2200 digital polarimeter with a sodium (D line) lamp. IR spectra were recorded on a Jasco Model A-202 spectrophotometer. ${ }^{1} \mathrm{H}-\mathrm{NMR}$ spectra and ${ }^{13} \mathrm{C}-\mathrm{NMR}$ spectra were obtained on JEOL JNM-EX270, JNM-GX400, JNM- $\alpha 400$, JNM-AL400 and JNM-ECX400 spectrometers in deuterated solvent using tetramethylsilane as an internal standard. Deuteriochloroform was used as a solvent, unless otherwise stated. Optical purity was determined by HPLC using an OJ-H column. High-resolution mass spectra were obtained on a Waters LCT Piemier XE (ESI) or JEOL JMS-700 (FAB). Preparative and analytical TLC were carried 
out on silica gel plate (Kieselgel 60 F254, E. Merck AG., Germany) using UV light and/or 5\% molybdophosphoric acid in ethanol for detection. Kanto silica $60 \mathrm{~N}$ (spherical, neutral, 105-210 $\mu \mathrm{m}$ ) was used for column chromatography.

(R)-tert-Butyl(3-(4-methoxybenzyloxy)pent-4-ynyloxy)diphenylsilane (7). To a suspension of $\mathrm{Ti}(\mathrm{OiPr})_{4}$ (4.28 mL, $14.6 \mathrm{mmol})$ and MS4A (4.9 g) in $\mathrm{CH}_{2} \mathrm{Cl}_{2}(100 \mathrm{~mL})$ was added (-)-DET (3.32 $\mathrm{mL}$, $19.5 \mathrm{mmol})$ at $-25{ }^{\circ} \mathrm{C}$. To the mixture were added $4(3.31 \mathrm{~g}, 9.73 \mathrm{mmol})$ and $\mathrm{t}$-BuOOH $(3.17 \mathrm{~mL}$, $29.2 \mathrm{mmol})$; the solution was stirred overnight. The reaction was quenched by L-(+)-tartaric acid $(12.4 \mathrm{~g}, 82.6 \mathrm{mmol})$ aqueous and iron (II) sulfate heptahydrate (12.2 g, $43.9 \mathrm{mmol})$. The mixture was extracted with $\mathrm{Et}_{2} \mathrm{O}$, and the organic extracts were dried $\left(\mathrm{Na}_{2} \mathrm{SO}_{4}\right)$, and concentrated in vacuo. The crude product was purified by silica gel column chromatography using hexane-ethyl acetate $(3: 1)$ to give an alcohol $(3.38 \mathrm{~g}, 98 \%, 95 \% \mathrm{ee})$ as a colorless oil: $[\alpha]^{23}{ }_{\mathrm{D}}+14.7$ (c 1.00, $\left.\mathrm{CHCl}_{3}\right)$; IR (film) 3437, 3048, 1428, 1110, 936, $822 \mathrm{~cm}^{-1} ;{ }^{1} \mathrm{H}-\mathrm{NMR}(400 \mathrm{MHz}) \delta 1.06(9 \mathrm{H}, \mathrm{s}), 1.81(2 \mathrm{H}, \mathrm{td}, J=12.1,6.0 \mathrm{~Hz})$, $2.98(1 \mathrm{H}, \mathrm{td}, J=4.7 .2 .5 \mathrm{~Hz}), 3.13(1 \mathrm{H}, \mathrm{td}, J=6.0,2.5 \mathrm{~Hz}), 3.63(1 \mathrm{H}, \mathrm{m}), 3.80(2 \mathrm{H}, \mathrm{m}), 3.91(1 \mathrm{H}, \mathrm{m})$, $7.40(6 \mathrm{H}, \mathrm{m}), 7.66(4 \mathrm{H}, \mathrm{m}) ;{ }^{13} \mathrm{C}-\mathrm{NMR}(100 \mathrm{MHz}) \delta 19.2,26.8,34.8,53.7,58.5,60.7,61.6,127.7$, 129.7, 133.6, 135.5. ESI-MS: calcd for $\mathrm{C}_{21} \mathrm{H}_{29} \mathrm{O}_{3} \mathrm{Si} 357.1886(\mathrm{M}+\mathrm{H})^{+}$, found, $m / z 357.1897$.

A stirred mixture of the alcohol (3.38 g, $9.49 \mathrm{mmol}), \mathrm{PPh}_{3}\left(7.47 \mathrm{~g}, 28.5 \mathrm{mmol}\right.$ ), and $\mathrm{NaHCO}_{3}$ $(0.80 \mathrm{~g}, 9.5 \mathrm{mmol})$ in $\mathrm{CCl}_{4}(100 \mathrm{~mL})$ was refluxed under argon atmosphere overnight. After completion of the reaction, $\mathrm{CCl}_{4}$ was removed under reduced pressure, and the residue was purified by silica gel column chromatography (hexane-ethyl acetate 40:1) to furnish an epoxy chloride (3.04 g, $86 \%$ ) as a colorless oil: $[\alpha]^{23}+12.9\left(\mathrm{c} 1.00, \mathrm{CHCl}_{3}\right)$; IR (film) $3049,1428,1111,939,822 \mathrm{~cm}^{-1}$; ${ }^{1} \mathrm{H}-$ NMR (400 MHz) $\delta 1.06(9 \mathrm{H}, \mathrm{s}), 1.81(2 \mathrm{H}, \mathrm{td}, J=11.2,5.6 \mathrm{~Hz}), 3.07(2 \mathrm{H}, \mathrm{m}), 3.56(2 \mathrm{H}, \mathrm{m}), 3.80(2 \mathrm{H}$, m), 7.41 (6H, m), $7.66(4 \mathrm{H}, \mathrm{m}) ;{ }^{13} \mathrm{C}-\mathrm{NMR}(100 \mathrm{MHz}) \delta 19.2,26.8,34.7,44.7,56.7,57.3,60.5,127.7$, 129.7, 133.5, 135.5. ESI-MS: calcd for $\mathrm{C}_{21} \mathrm{H}_{28} \mathrm{O}_{2} \mathrm{SiCl} 375.1547(\mathrm{M}+\mathrm{H})^{+}$, found, $m / z 375.1539$.

To a stirred solution of the epoxy chloride $(0.23 \mathrm{~g}, 0.63 \mathrm{mmol})$ in dry THF $(7 \mathrm{~mL})$ was added $\mathrm{n}$ BuLi (2.4 mL, 1.6 M solution in $n$-hexane, $3.79 \mathrm{mmol}$ ) dropwise at $-40{ }^{\circ} \mathrm{C}$ under argon atmosphere; and the mixture was stirred for an additional $2 \mathrm{~h}$. The mixture was quenched with saturated aqueous $\mathrm{NH}_{4} \mathrm{Cl}$, and the mixture was extracted with ethyl acetate. The organic extracts were dried $\left(\mathrm{Na}_{2} \mathrm{SO}_{4}\right)$, and concentrated in vacuo. The residue was purified by silica gel column chromatography (hexaneethyl acetate $7: 1)$ to give an alcohol $(0.18 \mathrm{~g}, 87 \%)$ as a colorless oil: $[\alpha]^{23}{ }_{\mathrm{D}}+3.67$ (c 1.00, $\left.\mathrm{CHCl}_{3}\right)$; IR (film) 3422, 3304, 3071, 1428, 1111, $823 \mathrm{~cm}^{-1} ;{ }^{1} \mathrm{H}-\mathrm{NMR}(400 \mathrm{MHz}) \delta 1.06(9 \mathrm{H}, \mathrm{s}), 1.92(1 \mathrm{H}$, tdd, $J=14.0,6.3,3.6 \mathrm{~Hz}), 2.05(1 \mathrm{H}, \mathrm{tdd}, J=14.0,8.0,4.3 \mathrm{~Hz}), 2.48(1 \mathrm{H}, \mathrm{d}, J=5.8 \mathrm{~Hz}), 3.34(1 \mathrm{H}, \mathrm{d}$, $J=5.8 \mathrm{~Hz}), 3.85(1 \mathrm{H}, \mathrm{ddd}, J=12.0,6.3,4.3 \mathrm{~Hz}), 4.07(1 \mathrm{H}, \mathrm{ddd}, J=12.0,8.0,3.6 \mathrm{~Hz}), 4.71(1 \mathrm{H}, \mathrm{m})$, $7.42(6 \mathrm{H}, \mathrm{m}), 7.69$ (4H, m); ${ }^{13} \mathrm{C}-\mathrm{NMR}(100 \mathrm{MHz}) \delta 19.0,26.8,38.5,61.5,61.7,73.0,84.4,127.8$, 129.9, 132.8, 135.6. ESI-MS: calcd for $\mathrm{C}_{21} \mathrm{H}_{27} \mathrm{O}_{2} \mathrm{Si} 339.1780(\mathrm{M}+\mathrm{H})^{+}$, found, $m / z 339.1775$.

To a solution of the alcohol $(0.10 \mathrm{~g}, 0.30 \mathrm{mmol})$ in anhydrous $\mathrm{CH}_{2} \mathrm{Cl}_{2}(7 \mathrm{~mL})$ were added 4-methoxybenzyl trichloroacetimidate $(0.493 \mathrm{~g}, 1.74 \mathrm{mmol})$ and $\mathrm{TfOH}$ (cat.) at $0{ }^{\circ} \mathrm{C}$, and the mixture was stirred overnight. The reaction was quenched with saturated aqueous $\mathrm{NH}_{4} \mathrm{Cl}$, and extracted with ethyl acetate. The organic extracts were dried $\left(\mathrm{Na}_{2} \mathrm{SO}_{4}\right)$, and concentrated in vacuo. The residue was purified by silica gel column chromatography (hexane-ethyl acetate $7: 1)$ to give $7(0.12 \mathrm{~g}, 90 \%)$ as a colorless oil: $[\alpha]_{\mathrm{D}}^{23}+45.1$ (c 1.02, $\mathrm{CHCl}_{3}$ ); IR (film) 3286, 1514, 1249, 1111, $823 \mathrm{~cm}^{-1}$; ${ }^{1} \mathrm{H}-\mathrm{NMR}$ $(400 \mathrm{MHz}) \delta 0.94(9 \mathrm{H}, \mathrm{s}), 1.91(2 \mathrm{H}, \mathrm{m}), 2.36(1 \mathrm{H}, \mathrm{d}, J=2.1 \mathrm{~Hz}), 3.72(5 \mathrm{H}, \mathrm{m}), 4.34(2 \mathrm{H}, \mathrm{m}), 4.66(1 \mathrm{H}$, 
$\mathrm{d}, J=11.2 \mathrm{~Hz}), 6.77(2 \mathrm{H}, \mathrm{m}), 7.20(2 \mathrm{H}, \mathrm{m}), 7.31(6 \mathrm{H}, \mathrm{m}), 7.56(4 \mathrm{H}, \mathrm{m}) ;{ }^{13} \mathrm{C}-\mathrm{NMR}(100 \mathrm{MHz}) \delta 19.2$, 26.8, 38.7, 55.2, 59.7, 65.0, 70.3, 73.8, 83.0, 113.8, 127.6, 129.6, 133.7, 135.5, 159.2. ESI-MS: calcd for $\mathrm{C}_{29} \mathrm{H}_{34} \mathrm{O}_{3} \mathrm{SiK} 497.1914(\mathrm{M}+\mathrm{K})^{+}$, found, $m / z 497.1911$.

(R)-Metyl-6-(tert-Butyldiphenylsilyloxy)-4-(4-methoxybenzyloxy)hex-2-ynoate (8). To a solution of 7 $(50.8 \mathrm{mg}, 0.11 \mathrm{mmol})$ in THF $(1.5 \mathrm{~mL})$ was added dropwise $n$-BuLi $(0.3 \mathrm{~mL}, 1.6 \mathrm{M}$ solution in hexane, $0.48 \mathrm{mmol}$ ) at $-78{ }^{\circ} \mathrm{C}$, and the mixture was stirred at the same temperature for $1 \mathrm{~h}$. Methyl chloroformate $(0.09 \mathrm{~mL}, 1.11 \mathrm{mmol})$ was added dropwise to the mixture; the resulting mixture was stirred at $0{ }^{\circ} \mathrm{C}$ for $2.5 \mathrm{~h}$. After being quenched with saturated aqueous $\mathrm{NH}_{4} \mathrm{Cl}$, the mixture extracted with ethyl acetate. The organic layer was dried $\left(\mathrm{Na}_{2} \mathrm{SO}_{4}\right)$, and concentrated in vacuo. The residue was purified by silica gel column chromatography (hexane-ethyl acetate 9:1) to give 8 (56.4 mg, 99\%) as a colorless oil: $[\alpha]^{23}{ }_{\mathrm{D}}+59.8\left(c 0.99, \mathrm{CHCl}_{3}\right.$ ); IR (film) 3071, 2233, 1719, 1249, $1111 \mathrm{~cm}^{-1}$; ${ }^{1} \mathrm{H}-\mathrm{NMR}$ $(400 \mathrm{MHz}) \delta 1.00(9 \mathrm{H}, \mathrm{s}), 2.01(2 \mathrm{H}, \mathrm{ddd}, J=12.7,7.6,6.0 \mathrm{~Hz}), 3.79(8 \mathrm{H}, \mathrm{m}), 4.43(1 \mathrm{H}, \mathrm{d}$, $J=11.2 \mathrm{~Hz}), 4.55(1 \mathrm{H}, \mathrm{d}, J=7.6,6.0 \mathrm{~Hz}), 4.74(1 \mathrm{H}, \mathrm{d}, J=11.2 \mathrm{~Hz}), 6.86(2 \mathrm{H}, \mathrm{m}), 7.26(2 \mathrm{H}, \mathrm{m}), 7.37$ $(6 \mathrm{H}, \mathrm{m}), 7.60(4 \mathrm{H}, \mathrm{m}) ;{ }^{13} \mathrm{C}-\mathrm{NMR}(100 \mathrm{MHz}) \delta 19.1,26.7,38.0,52.8,55.2,59.3,64.7,71.0,86.9$, $113.8,127.7,129.2,129.6,129.7,133.5,135.5$, 153.7, 159.4. ESI-MS: calcd for $\mathrm{C}_{31} \mathrm{H}_{36} \mathrm{O}_{5} \mathrm{SiK}$ $555.1969(\mathrm{M}+\mathrm{K})^{+}$, found, $m / z 555.1970$.

(R,E)-Methyl 6-(tert-butyldiphenylsilyloxy)-4-(4-methoxybenzyloxy)-3-methylhex-2-enoate (9). To a solution of 8 (90.8 mg, $0.18 \mathrm{mmol})$ in $\mathrm{MeOH}$ was added $\mathrm{PhSH}(36 \mu \mathrm{L}, 0.35 \mathrm{mmol})$ and $\mathrm{NaOMe}(0.18$ $\mathrm{mL}, 0.02 \mathrm{mmol}$ ) at room temperature. After being stirred at the same temperature for $3 \mathrm{~h}$, the reaction mixture was concentrated in vacuo. The residue was purified by silica gel column chromatography (hexane- ethyl acetate $9: 1)$ to give a methyl ester $(102.1 \mathrm{mg}, 93 \%)$ as a colorless oil: $[\alpha]^{23}-91.3(c$ 1.0, $\mathrm{CHCl}_{3}$ ); IR (film) 1705, 1513, 1248, $1110 \mathrm{~cm}^{-1} ;{ }^{1} \mathrm{H}-\mathrm{NMR}(400 \mathrm{MHz}) \delta 0.93(9 \mathrm{H}, \mathrm{s}), 1.63(1 \mathrm{H}, \mathrm{m})$, $2.02(1 \mathrm{H}, \mathrm{m}), 3.46(1 \mathrm{H}, \mathrm{m}), 3.50(1 \mathrm{H}, \mathrm{m}), 3.77(3 \mathrm{H}, \mathrm{s}), 3.79(3 \mathrm{H}, \mathrm{s}), 3.96(1 \mathrm{H}, \mathrm{dd}, J=2.5,9.9 \mathrm{~Hz})$, $4.04(1 \mathrm{H}, \mathrm{d}, J=10.8 \mathrm{~Hz}), 4.46(1 \mathrm{H}, \mathrm{d}, J=10.8 \mathrm{~Hz}), 6.35(1 \mathrm{H}, \mathrm{s}), 6.79(2 \mathrm{H}, \mathrm{m}), 7.07(2 \mathrm{H}, \mathrm{m}), 7.21$ $(3 \mathrm{H}, \mathrm{m}), 7.34(4 \mathrm{H}, \mathrm{m}), 7.43(4 \mathrm{H}, \mathrm{m}), 7.53(4 \mathrm{H}, \mathrm{m}) ;{ }^{13} \mathrm{C}-\mathrm{NMR}(100 \mathrm{MHz}) \delta 19.1,26.8,39.8,51.4,55.3$, $60.2,70.7,75.3,113.8,111.6,113.7,127.5,129.2,129.3,129.5,135.3,135.5,159.2,160.5,166.8$. ESI-MS: calcd for $\mathrm{C}_{37} \mathrm{H}_{42} \mathrm{O}_{5} \mathrm{SiSNa} 649.2420(\mathrm{M}+\mathrm{Na})^{+}$, found, $m / z$ 649.2440.

To a suspension of $\mathrm{CuI}(0.62 \mathrm{~g}, 3.2 \mathrm{mmol})$ in $\mathrm{THF}$ was added $\mathrm{MeMgBr}(6.7 \mathrm{~mL}, 0.95 \mathrm{M}$ in THF, $6.3 \mathrm{mmol}$ ) at $-78^{\circ} \mathrm{C}$; the solution was warmed to $-30{ }^{\circ} \mathrm{C}$ and stirred for $1.5 \mathrm{~h}$. The solution was cooled to $-78{ }^{\circ} \mathrm{C}$, and the methyl ester $(0.10 \mathrm{~g}, 0.16 \mathrm{mmol})$ was added. The reaction mixture was stirred at $-30{ }^{\circ} \mathrm{C}$ for $1 \mathrm{~h}$, then quenched with saturated aqueous $\mathrm{NH}_{4} \mathrm{Cl}$ and $\mathrm{NH}_{4} \mathrm{OH}$. The reaction mixture was extracted with ethyl acetate, and the organic layer was dried $\left(\mathrm{Na}_{2} \mathrm{SO}_{4}\right)$ and concentrated in vacuo. The residue was purified by silica gel column chromatography (benzene-hexane 7:1) to give 9 (75 mg, 87\%) as a colorless oil: $[\alpha]^{23}{ }_{\mathrm{D}}+64.0\left(c 0.50, \mathrm{CHCl}_{3}\right)$; IR (film) $1720,1428,1249,1111,822 \mathrm{~cm}^{-1} ;{ }^{1} \mathrm{H}-$ NMR (400 MHz) $\delta 0.96(9 \mathrm{H}, \mathrm{s}), 1.69(2 \mathrm{H}, \mathrm{m}), 2.05(3 \mathrm{H}, \mathrm{d}, J=1.0 \mathrm{~Hz}), 3.64(8 \mathrm{H}, \mathrm{m}), 3.99(1 \mathrm{H}, \mathrm{t}$, $J=6.6 \mathrm{~Hz}), 4.08(1 \mathrm{H}, \mathrm{d}, J=11.2 \mathrm{~Hz}), 4.34(1 \mathrm{H}, \mathrm{d}, J=11.2 \mathrm{~Hz}), 5.86(1 \mathrm{H}, \mathrm{s}), 6.77(2 \mathrm{H}, \mathrm{m}), 7.12$ $(2 \mathrm{H}, \mathrm{m}), 7.31(6 \mathrm{H}, \mathrm{m}), 7.56(4 \mathrm{H}, \mathrm{m}) ;{ }^{13} \mathrm{C}-\mathrm{NMR}(100 \mathrm{MHz}) \delta 14.3,19.2,26.8,37.2,51.0,55.2,59.9$, 70.6, 80.2, 113.8, 116.4, 127.6, 129.4, 129.6, 130.1, 133.7, 135.5, 158.9, 159.2, 167.0. ESI-MS: calcd for $\mathrm{C}_{32} \mathrm{H}_{40} \mathrm{O}_{5} \mathrm{SiNa} 555.2543(\mathrm{M}+\mathrm{Na})^{+}$, found, $m / z 555.2530$. 
(R,E)-Methyl 4-(4-methoxybenzyloxy)-3-methyl-6-oxohex-2-enoate (segment A, 2). To a solution of 9 $(0.33 \mathrm{~g}, 0.62 \mathrm{mmol})$ in THF $(6 \mathrm{~mL})$ was added reagent $\left(\mathrm{TBAF}-\mathrm{AcOH}-\mathrm{H}_{2} \mathrm{O}=1: 1: 50.1 \mathrm{M}\right.$ in THF, $0.3 \mathrm{mmol}$ ) at room temperature; the mixture was stirred at the same temperature overnight. After the addition of cold water, the mixture was extracted with $\mathrm{Et}_{2} \mathrm{O}$. The organic layer was dried $\left(\mathrm{Na}_{2} \mathrm{SO}_{4}\right)$ and concentrated in vacuo. The residue was purified by silica gel column chromatography (hexane-ethyl acetate $1: 1)$ to give an alcohol $(0.16 \mathrm{~g}, 88 \%)$ as a colorless oil: $[\alpha]^{23}{ }_{\mathrm{D}}+68.7\left(c 0.99, \mathrm{CHCl}_{3}\right)$; IR (film) 3429, 1718, 1654, 1613, 1513, 1156, $1035 \mathrm{~cm}^{-1}$; ${ }^{1} \mathrm{H}-\mathrm{NMR}(270 \mathrm{MHz}) \delta 1.84(2 \mathrm{H}, \mathrm{m}), 2.15(3 \mathrm{H}, \mathrm{d}$, $J=1.3 \mathrm{~Hz}), 3.73(5 \mathrm{H}, \mathrm{m}), 3.81(3 \mathrm{H}, \mathrm{s}), 3.98(1 \mathrm{H}, \mathrm{dd}, J=9.1,3.8 \mathrm{~Hz}), 4.20(1 \mathrm{H}, \mathrm{d}, J=11.2 \mathrm{~Hz}), 4.48$ $(1 \mathrm{H}, \mathrm{d}, J=11.2 \mathrm{~Hz}), 5.95(1 \mathrm{H}, \mathrm{s}), 6.89(2 \mathrm{H}, \mathrm{m}), 7.23(2 \mathrm{H}, \mathrm{m}) ;{ }^{13} \mathrm{C}-\mathrm{NMR}(67.5 \mathrm{MHz}) \delta 14.4,29.7$, 36.3, 51.1, 55.2, 60.4, 70.6, 82.03, 113.9, 116.6, 128.3, 129.5, 129.6, 157.7, 159.4, 166.8. ESI-MS: calcd for $\mathrm{C}_{16} \mathrm{H}_{22} \mathrm{O}_{5} \mathrm{Na} 317.1365(\mathrm{M}+\mathrm{Na})^{+}$, found, $m / z 317.1363$.

To a mixture of PCC (35 mg, $0.16 \mathrm{mmol})$ and Celite in $\mathrm{CH}_{2} \mathrm{Cl}_{2}(2 \mathrm{~mL})$ was added the alcohol $(31.7 \mathrm{mg}, 0.11 \mathrm{mmol})$ at $0{ }^{\circ} \mathrm{C}$; the mixture was stirred at room temperature for $30 \mathrm{~min}$. After concentration of the reaction mixture, the residue was purified by silica gel column chromatography (Et ${ }_{2} \mathrm{O}$-hexane $\left.2: 1\right)$ to give segment $\mathbf{A}(26.7 \mathrm{mg}, 85 \%)$ as a colorless oil: $[\alpha]^{23}{ }_{\mathrm{D}}+28.9\left(c 0.91, \mathrm{CHCl}_{3}\right)$; IR (film) 1720, 1655, 1612, 1513, 1248, $1034 \mathrm{~cm}^{-1} ;{ }^{1} \mathrm{H}-\mathrm{NMR}\left(270 \mathrm{MHz}, \mathrm{C}_{6} \mathrm{D}_{6}\right) \delta 1.90(1 \mathrm{H}$, ddd, $J=1.1,3.6,16.6 \mathrm{~Hz}), 2.14(3 \mathrm{H}, \mathrm{m}), 2.34(1 \mathrm{H}, \mathrm{ddd}, J=2.5,9.2,16.6 \mathrm{~Hz}), 3.38(3 \mathrm{H}, \mathrm{s}), 3.53(3 \mathrm{H}, \mathrm{s})$, $4.05(1 \mathrm{H}, \mathrm{m}), 4.07(1 \mathrm{H}, \mathrm{d}, J=11.2 \mathrm{~Hz}), 4.32(1 \mathrm{H}, \mathrm{d}, J=11.2 \mathrm{~Hz}), 6.09(1 \mathrm{H}, \mathrm{m}), 6.84(2 \mathrm{H}, \mathrm{m}), 7.18$ $(2 \mathrm{H}, \mathrm{m}), 9.38(1 \mathrm{H}, \mathrm{dd}, J=1.1,2.5 \mathrm{~Hz}),{ }^{13} \mathrm{C}-\mathrm{NMR}\left(67.5 \mathrm{MHz}, \mathrm{C}_{6} \mathrm{D}_{6}\right) \delta 14.3,47.5,50.7,54.7,70.7$, 77.6, 78.2, 114.1, 117.4, 129.7, 130.0, 156.6, 166.3, 198.3. ESI-MS: calcd for $293.1389(\mathrm{M}+\mathrm{H})^{+}$, found, $m / z 293.1402$.

(R)-3-(2,2-Dimethyl-1,3-dioxolan-4-yl)propanoic acid (11). To a solution of $\mathrm{NaIO}_{4}(3.78 \mathrm{~g}, 17.7 \mathrm{mmol})$ in $\mathrm{CH}_{2} \mathrm{Cl}_{2}(60 \mathrm{~mL})$ and $\mathrm{H}_{2} \mathrm{O}(30 \mathrm{~mL})$ was added $10(1.91 \mathrm{~g}, 11.8 \mathrm{mmol})$ at $0{ }^{\circ} \mathrm{C}$; the mixture was stirred at room temperature for $1.5 \mathrm{~h}$. After the addition of $\mathrm{Ph}_{3} \mathrm{PCHCO}_{2} \mathrm{Me}(7.89 \mathrm{~g}, 23.6 \mathrm{mmol})$ at 0 ${ }^{\circ} \mathrm{C}$, the mixture was stirred at room temperature overnight. The organic layer was separated and the aqueous layer was extracted with $\mathrm{CHCl}_{3}$ three times. The combined organic layers were washed with brine, dried $\left(\mathrm{Na}_{2} \mathrm{SO}_{4}\right)$, and concentrated in vacuo. The residue was purified by silica gel column chromatography (hexane-ethyl acetate $3: 1)$ to give an $\alpha, \beta$-unsaturated ester $(1.84 \mathrm{~g}, 84 \%, E: Z=1: 3)$ as a colorless oil.

The ester $(1.02 \mathrm{~g}, 5.48 \mathrm{mmol})$ was dissolved in EtOH $(55 \mathrm{~mL})$ in the presence of Raney Ni W-4. The mixture was stirred at room temperature under hydrogen atmosphere overnight. After filtration, the filtrate was concentrated at $110^{\circ} \mathrm{C}$ to afford the corresponding ester as a crude oil. To a solution of the ester in THF $(17 \mathrm{~mL})$ was added $1.5 \mathrm{M} \mathrm{LiOH}$ aqueous $(17 \mathrm{~mL})$ at $0{ }^{\circ} \mathrm{C}$. The mixture was stirred at $0{ }^{\circ} \mathrm{C}$ for $3 \mathrm{~h}$. The mixture was acidified to $\mathrm{pH} 4$ with $10 \%$ aqueous citric acid and extracted with ethyl acetate three times. The combined organic layers were washed with brine, dried $\left(\mathrm{Na}_{2} \mathrm{SO}_{4}\right)$, and concentrated in vacuo to give $11(0.935 \mathrm{~g}, 98 \%)$ as a colorless oil: $\left.[\alpha]^{23}{ }_{\mathrm{D}}+1.2(c) 1.00, \mathrm{CHCl}_{3}\right)$; IR (film) 2987, 1712, 1215, 1154, $1073 \mathrm{~cm}^{-1}$; ${ }^{1} \mathrm{H}-\mathrm{NMR}(270 \mathrm{MHz}) \delta 1.35(3 \mathrm{H}, \mathrm{s}), 1.42(3 \mathrm{H}, \mathrm{s}), 1.89(2 \mathrm{H}$, m), $2.51(2 \mathrm{H}, \mathrm{m}), 3.57(1 \mathrm{H}, \mathrm{dd}, J=6.5,7.8 \mathrm{~Hz}), 4.06(1 \mathrm{H}, \mathrm{dd}, J=5.9,7.8 \mathrm{~Hz}), 4.14(1 \mathrm{H}, \mathrm{m})$; ${ }^{13} \mathrm{C}$ - NMR $(67.5 \mathrm{MHz}) \delta 25.6,26.9,28.5,30.2,68.9$, 74.7, 109.1, 178.9. ESI-MS: calcd for $\mathrm{C}_{8} \mathrm{H}_{15} \mathrm{O}_{4}$ $175.0970(\mathrm{M}+\mathrm{H})^{+}$, found, $m / z 175.0968$. 
(R)-4-Benzyl-3-((R)-3-((R)-2,2-dimethyl-1,3-dioxolan-4-yl)-2-methylpropanoyl)oxazolidin-2-one (12). To a solution of $11(6.10 \mathrm{~g}, 35.0 \mathrm{mmol})$ in THF $(325 \mathrm{~mL})$ were added $\mathrm{Et}_{3} \mathrm{~N}(15.0 \mathrm{~mL}, 0.190 \mathrm{~mol})$ and PivCl $(6.40 \mathrm{~mL}, 52.5 \mathrm{mmol})$ at $0{ }^{\circ} \mathrm{C}$. After $2 \mathrm{~h}$, LiCl $(7.42 \mathrm{~g}, 175 \mathrm{mmol})$ and $(R)$-4-benzyl-2oxazolidinone $(9.30 \mathrm{~g}, 52.5 \mathrm{mmol})$ were added to the reaction mixture, and then the mixture was stirred at room temperature overnight. The reaction was quenched by the addition of saturated aqueous $\mathrm{NH}_{4} \mathrm{Cl}$ at $0{ }^{\circ} \mathrm{C}$, then the resulting slurry was extracted with ethyl acetate three times. The combined organic layers were washed with brine, dried $\left(\mathrm{Na}_{2} \mathrm{SO}_{4}\right)$, and concentrated in vacuo. The residue was purified by silica gel column chromatography (hexane-ethyl acetate 3:1) to give an amide (10.8 g, 92\%) as a colorless oil: $[\alpha]^{24}-42.4\left(c\right.$ 1.01, $\left.\mathrm{CHCl}_{3}\right)$; IR (film) 2984, 1782, 1690, 1382, 1212, 1054 $\mathrm{cm}^{-1}$; ${ }^{1} \mathrm{H}-\mathrm{NMR}(400 \mathrm{MHz}) \delta 1.35(3 \mathrm{H}, \mathrm{s}), 1.42(3 \mathrm{H}, \mathrm{s}), 1.96(2 \mathrm{H}, \mathrm{m}), 2.78(1 \mathrm{H}, \mathrm{dd}, J=9.8,13.2 \mathrm{~Hz})$, $3.07(2 \mathrm{H}, \mathrm{t}, J=7.8 \mathrm{~Hz}), 3.30(1 \mathrm{H}, \mathrm{dd}, J=3.4,13.2 \mathrm{~Hz}), 3.60(1 \mathrm{H}, \mathrm{dd}, J=6.8,7.8 \mathrm{~Hz}), 4.08(1 \mathrm{H}, \mathrm{dd}$, $J=5.9,7.8 \mathrm{~Hz}), 4.64(3 \mathrm{H}, \mathrm{m}), 4.67(1 \mathrm{H}, \mathrm{m}), 7.27(5 \mathrm{H}, \mathrm{m}) ;{ }^{13} \mathrm{C}-\mathrm{NMR}(100 \mathrm{MHz}) \delta 25.7,27.0,28.2$, 32.0, 37.9, 55.1, 66.2, 69.2, 74.9, 108.9, 127.2, 128.8, 129.3, 135.1, 153.3, 172.5, 180.1. ESI-MS: calcd for $\mathrm{C}_{18} \mathrm{H}_{23} \mathrm{NO}_{5} \mathrm{Na} 356.1474(\mathrm{M}+\mathrm{Na})^{+}$, found, $m / z 356.1489$.

To a solution of LHMDS (73.0 mL, 1.0 M solution in THF, $73.0 \mathrm{mmol}$ ) was added the amide (12.2 g, $36.5 \mathrm{mmol})$ in THF $(400 \mathrm{~mL})$ at $-40^{\circ} \mathrm{C}$. After $1.5 \mathrm{~h}$, MeI $(22.7 \mathrm{~mL}, 0.365 \mathrm{~mol})$ was added to the reaction mixture. The mixture was stirred at $-20{ }^{\circ} \mathrm{C}$ for $4 \mathrm{~h}$. The reaction was quenched by the addition of saturated aqueous $\mathrm{NH}_{4} \mathrm{Cl}$ at $0{ }^{\circ} \mathrm{C}$, then the resulting slurry was extracted with ethyl acetate three times. The combined organic layers were washed with brine, dried $\left(\mathrm{Na}_{2} \mathrm{SO}_{4}\right)$, and concentrated in vacuo. The residue was purified by silica gel column chromatography (hexane-ethyl acetate $3: 1$ ) to give 12 (10.8 g, 85\%) as a white needles: m.p. 93-93.5 ${ }^{\circ} \mathrm{C}$ (ethyl acetate); $[\alpha]^{24}-65.4(c 1.00$, $\mathrm{CHCl}_{3}$ ); IR (film) 2983, 1780, 1697, 1381, 1213, 1159, 1085, $1053 \mathrm{~cm}^{-1} ;{ }^{1} \mathrm{H}-\mathrm{NMR}(400 \mathrm{MHz}) \delta 1.26$ $(3 \mathrm{H}, \mathrm{d}, J=7.3 \mathrm{~Hz}), 1.30(3 \mathrm{H}, \mathrm{s}), 1.36(3 \mathrm{H}, \mathrm{s}), 1.66(1 \mathrm{H}, \mathrm{ddd}, J=4.4,5.4,13.7 \mathrm{~Hz}), 2.05(1 \mathrm{H}$, ddd, $J=8.8,8.3,13.7 \mathrm{~Hz}), 2.79(1 \mathrm{H}, \mathrm{dd}, J=9.8,13.2 \mathrm{~Hz}), 3.26(1 \mathrm{H}, \mathrm{dd}, J=3.4,13.2 \mathrm{~Hz}), 3.50(1 \mathrm{H}, \mathrm{dd}$, $J=7.3,7.8 \mathrm{~Hz}), 4.01(1 \mathrm{H}, \mathrm{m}), 4.03(1 \mathrm{H}, \mathrm{dd}, J=5.4,7.8 \mathrm{~Hz}), 4.17(3 \mathrm{H}, \mathrm{m}), 4.67(1 \mathrm{H}, \mathrm{m}), 7.28(5 \mathrm{H}$, $\mathrm{m}) ;{ }^{13} \mathrm{C}$ - NMR (100 MHz) $\delta$ 18.2, 25.7, 26.9, 34.7, 38.0, 38.1, 55.4, 66.0, 69.5, 74.2, 108.9, 127.2, 128.8, 129.3, 153.2, 176.9, 180.1. ESI-MS: calcd for $\mathrm{C}_{19} \mathrm{H}_{26} \mathrm{NO}_{5} \mathrm{Na}(\mathrm{M}+\mathrm{Na})^{+} 348.1811$, found, $\mathrm{m} / z$ 348.1805 .

(2R,4R)-5-(Benzyloxy)-4-methylpentane-1,2-diol (13). To a solution of 12 (7.44 g, $21.4 \mathrm{mmol})$ in THF$\mathrm{MeOH}-\mathrm{H}_{2} \mathrm{O}(4: 4: 1),(220 \mathrm{~mL})$ was added $\mathrm{LiBH}_{4}(2.1 \mathrm{~g}, 86 \mathrm{mmol})$ at $0{ }^{\circ} \mathrm{C}$. The mixture was stirred at room temperature for $2.5 \mathrm{~h}$. The reaction was quenched by the addition of saturated aqueous $\mathrm{NH}_{4} \mathrm{Cl}$ at $0{ }^{\circ} \mathrm{C}$, then the resulting slurry was extracted with $\mathrm{Et}_{2} \mathrm{O}$ three times. The combined organic layers were washed with brine, dried $\left(\mathrm{Na}_{2} \mathrm{SO}_{4}\right)$, and concentrated in vacuo. The residue was purified by silica gel chromatography (hexane-ethyl acetate $(1: 1)$ ) to give an alcohol. To a solution of the alcohol in DMF $(220 \mathrm{~mL})$ was added $\mathrm{BnBr}(8 \mathrm{~mL}, 64.3 \mathrm{mmol})$, TBAI $(3.2 \mathrm{~g}, 8.57 \mathrm{mmol})$ and $\mathrm{NaH}(3.1 \mathrm{~g}, 64.3 \mathrm{mmol})$ at $0{ }^{\circ} \mathrm{C}$. The mixture was stirred at room temperature overnight. The reaction was quenched by the addition of saturated aqueous $\mathrm{NH}_{4} \mathrm{Cl}$ at $0{ }^{\circ} \mathrm{C}$, then the resulting slurry was extracted with $\mathrm{Et}_{2} \mathrm{O}$ three times. The combined organic layers were washed with brine, dried $\left(\mathrm{Na}_{2} \mathrm{SO}_{4}\right)$, and concentrated in vacuo. The residue was purified by silica gel column chromatography (hexane-ethyl acetate 10:1) to give an acetonide $(5.09 \mathrm{~g}, 90 \%)$ as a colorless oil: $[\alpha]_{\mathrm{D}}^{24}-11.5\left(c 1.03, \mathrm{CHCl}_{3}\right)$; IR (film) 2984, 1454, 1368, 1213, 1098, $1061 \mathrm{~cm}^{-1}$; ${ }^{1} \mathrm{H}-\mathrm{NMR}(400 \mathrm{MHz}) \delta 0.91(3 \mathrm{H}, \mathrm{d}, J=6.8 \mathrm{~Hz}), 1.29(7 \mathrm{H}, \mathrm{m}), 1.71(1 \mathrm{H}$, 
ddd, $J=5.8,8.3,13.7 \mathrm{~Hz}), 1.89(1 \mathrm{H}, \mathrm{m}), 3.24(2 \mathrm{H}, \mathrm{m}), 3.42(1 \mathrm{H}, \mathrm{t}, J=7.8 \mathrm{~Hz}), 3.97(1 \mathrm{H}, \mathrm{dd}, J=7.8$, $5.8 \mathrm{~Hz}), 4.12(1 \mathrm{H}, \mathrm{tt}, J=7.8,5.8 \mathrm{~Hz}), 4.43(2 \mathrm{H}, \mathrm{s}), 7.26(5 \mathrm{H}, \mathrm{m}) ;{ }^{13} \mathrm{C}-\mathrm{NMR}(100 \mathrm{MHz}) \delta 17.1,25.8$, 27.1, 30.7, 37.8, 69.9, 72.9, 74.2, 108.5, 127.4, 127.5, 128.3, 138.6. ESI-MS: calcd for $\mathrm{C}_{16} \mathrm{H}_{25} \mathrm{O}_{3}$ $265.1804(\mathrm{M}+\mathrm{H})^{+}$, found, $m / z 265.1803$.

To a solution of the acetonide $(0.73 \mathrm{~g}, 2.8 \mathrm{mmol})$ in $\mathrm{DMF}(30 \mathrm{~mL})$ were added $\mathrm{TsOH} \cdot \mathrm{H}_{2} \mathrm{O}(1.6 \mathrm{~g}$, $8.3 \mathrm{mmol})$ and $\mathrm{H}_{2} \mathrm{O}(10 \mathrm{~mL})$ at $0{ }^{\circ} \mathrm{C}$; the mixture was stirred at $30{ }^{\circ} \mathrm{C}$ under $80 \mathrm{mmHg}$ for $3 \mathrm{~h}$. After the addition of saturated aqueous $\mathrm{NH}_{4} \mathrm{Cl}$, the mixture was extracted with $\mathrm{Et}_{2} \mathrm{O}$. The organic layer was dried $\left(\mathrm{Na}_{2} \mathrm{SO}_{4}\right)$, and concentrated in vacuo. The residue was purified by silica gel column chromatography (hexane-ethyl acetate $1: 1)$ to give $13\left(0.66 \mathrm{~g}\right.$, quant.) as a colorless oil: $[\alpha]_{D}^{24}+16.0(c$ 0.99, $\mathrm{CHCl}_{3}$ ); IR (film) 3375, 1454, 1363, $1074 \mathrm{~cm}^{-1} ;{ }^{1} \mathrm{H}-\mathrm{NMR}(400 \mathrm{MHz}) \delta 0.87(3 \mathrm{H}, \mathrm{d}, J=6.8 \mathrm{~Hz})$, $1.39(2 \mathrm{H}, \mathrm{m}), 1.93(2 \mathrm{H}, \mathrm{m}), 3.22(1 \mathrm{H}, \mathrm{m}), 3.37(2 \mathrm{H}, \mathrm{m}), 3.52(2 \mathrm{H}, \mathrm{m}), 3.70(1 \mathrm{H}, \mathrm{m}), 4.47(2 \mathrm{H}, \mathrm{s}), 7.24$ $(5 \mathrm{H}, \mathrm{m}) ;{ }^{13} \mathrm{C}-\mathrm{NMR}(100 \mathrm{MHz}) \delta 18.2,31.8,39.6,67.4,71.0,73.3,76.6,127.7,127.8,128.5,137.6$. ESI-MS: calcd for $\mathrm{C}_{13} \mathrm{H}_{20} \mathrm{O}_{3} \mathrm{Na} 247.1310(\mathrm{M}+\mathrm{Na})^{+}$, found, $\mathrm{m} / z$ 247.1309.

(2R,4R)-5-(Benzyloxy)-2-(tert-butyldimethylsilyloxy)-4-methylpentan-1-ol (14). To a solution of 13 (3.39 $\mathrm{g}, 15.1 \mathrm{mmol})$ in $\mathrm{CH}_{2} \mathrm{Cl}_{2}(75 \mathrm{~mL})$ and pyridine $(75 \mathrm{~mL})$ was added $\mathrm{PivCl}(2.8 \mathrm{~mL}, 22.7 \mathrm{mmol})$ at $0{ }^{\circ} \mathrm{C}$; the mixture was stirred at room temperature for $1.5 \mathrm{~h}$. The reaction was quenched with saturated aqueous $\mathrm{NH}_{4} \mathrm{Cl}$, and the mixture was extracted with $\mathrm{Et}_{2} \mathrm{O}$. The organic layer was dried $\left(\mathrm{Na}_{2} \mathrm{SO}_{4}\right)$, and concentrated in vacuo. The residue was purified by silica gel column chromatography (hexane-ethyl acetate $4: 1)$ to give an alcohol $(4.57 \mathrm{~g}, 98 \%)$ as a colorless oil: $[\alpha]^{24}+10.7\left(c 1.01, \mathrm{CHCl}_{3}\right)$; IR (film) 3442, 1730, 1455, 1285, 1164, $1097 \mathrm{~cm}^{-1} ;{ }^{1} \mathrm{H}-\mathrm{NMR}(400 \mathrm{MHz}) \delta 0.88(3 \mathrm{H}, \mathrm{d}, J=7.3 \mathrm{~Hz}), 1.15$ $(9 \mathrm{H}, \mathrm{s}), 1.33(1 \mathrm{H}, \mathrm{ddd}, J=14.4,6.8,2.9 \mathrm{~Hz}), 1.46(1 \mathrm{H}, \mathrm{m}), 1.95(1 \mathrm{H}, \mathrm{m}), 2.98(1 \mathrm{H}, \mathrm{br}), 3.22(1 \mathrm{H}, \mathrm{dd}$, $J=9.8,6.3 \mathrm{~Hz}), 3.32(1 \mathrm{H}, \mathrm{dd}, J=9.8,5.4 \mathrm{~Hz}), 3.84(1 \mathrm{H}, \mathrm{m}), 3.96(2 \mathrm{H}, \mathrm{m}), 4.46(2 \mathrm{H}, \mathrm{s}), 7.26$ $(5 \mathrm{H}, \mathrm{m}) ;{ }^{13} \mathrm{C}-\mathrm{NMR}(100 \mathrm{MHz}) \delta 17.7,27.2,31.2,38.8,39.0,68.8,73.1,76.2,127.7,128.3,128.4$, 138.0, 178.6. ESI-MS: calcd for $\mathrm{C}_{18} \mathrm{H}_{28} \mathrm{O}_{4} \mathrm{Na} 331.1885(\mathrm{M}+\mathrm{Na})^{+}$, found, $m / z 331.1880$.

To a solution of the alcohol $(4.57 \mathrm{~g}, 14.8 \mathrm{mmol})$ in DMF $(150 \mathrm{~mL})$ were added imidazole $(3.03 \mathrm{~g}$, $44.5 \mathrm{mmol})$ and $\mathrm{TBSCl}(6.7 \mathrm{~g}, 44.5 \mathrm{mmol})$ at $0{ }^{\circ} \mathrm{C}$; the mixture was stirred at room temperature overnight. After the addition of saturated aqueous $\mathrm{NH}_{4} \mathrm{Cl}$, the mixture was extracted with $\mathrm{Et}_{2} \mathrm{O}$. The organic layer dried $\left(\mathrm{Na}_{2} \mathrm{SO}_{4}\right)$, and concentrated in vacuo. The residue was purified by silica gel column chromatography (hexane-ethyl acetate $7: 1)$ to give a silyl ether $(6.31 \mathrm{~g}$, quant.) as a colorless oil: $[\alpha]_{\mathrm{D}}^{24}+10.6\left(c\right.$ 1.02, $\left.\mathrm{CHCl}_{3}\right)$; IR (film) 1733, 1160, $836 \mathrm{~cm}^{-1} ;{ }^{1} \mathrm{H}-\mathrm{NMR}(400 \mathrm{MHz}) \delta 0.09(6 \mathrm{H}, \mathrm{s})$, $0.88(9 \mathrm{H}, \mathrm{s}), 0.94(3 \mathrm{H}, \mathrm{m}), 1.20(9 \mathrm{H}, \mathrm{s}), 1.28(1 \mathrm{H}, \mathrm{m}), 1.63(1 \mathrm{H}, \mathrm{ddd}, J=4.5,7.9,13.7 \mathrm{~Hz}), 1.97(1 \mathrm{H}$, m), $3.27(1 \mathrm{H}, \mathrm{dd}, J=6.1,9.2 \mathrm{~Hz}), 3.33(1 \mathrm{H}, \mathrm{dd}, J=6.1,9.2 \mathrm{~Hz}), 3.97(3 \mathrm{H}, \mathrm{m}), 4.50(2 \mathrm{H}, \mathrm{s}), 7.34$ $(5 \mathrm{H}, \mathrm{m}) ;{ }^{13} \mathrm{C}$ - NMR $(100 \mathrm{MHz}) \delta-4.7,-4.4,17.1,18.0,25.5,25.8,27.1,27.2,29.5,38.7,38.8,68.1$, 68.4, 76.2, 127.3, 127.4, 128.3, 138.7, 178.5. ESI-MS: calcd for $\mathrm{C}_{24} \mathrm{H}_{42} \mathrm{O}_{4} \mathrm{SiNa} 445.2750(\mathrm{M}+\mathrm{Na})^{+}$, found, $m / z 445.2747$.

To a solution of the silyl ether $(11.7 \mathrm{mg}, 27.7 \mu \mathrm{mol})$ in $\mathrm{CH}_{2} \mathrm{Cl}_{2}(0.3 \mathrm{~mL})$ was added DIBAL-H $(0.08 \mathrm{~mL}, 1.03 \mathrm{M}$ in $\mathrm{n}$-hexane, $83.1 \mu \mathrm{mol})$ at $-78^{\circ} \mathrm{C}$. After being stirred for $1 \mathrm{~h}$ then the reaction was quenched by potassium-sodium tartrate aqueous. The mixture was extracted with $\mathrm{CHCl}_{3}$, dried $\left(\mathrm{Na}_{2} \mathrm{SO}_{4}\right)$, and concentrated in vacuo. The crude product was purified by silica gel column chromatography using hexane-ethyl acetate $(5: 1)$ to give $\mathbf{1 4}(9.1 \mathrm{mg}, 97 \%)$ as a colorless oil: $[\alpha]^{24}{ }_{\mathrm{D}}^{-}$ 2.3 (c 0.97, $\mathrm{CHCl}_{3}$ ); IR (film) 3437, 2857, $836 \mathrm{~cm}^{-1} ;{ }^{1} \mathrm{H}-\mathrm{NMR}(400 \mathrm{MHz}) \delta 0.08(6 \mathrm{H}, \mathrm{s}), 0.90(9 \mathrm{H}, \mathrm{s})$, 
$0.95(3 \mathrm{H}, \mathrm{m}), 1.29(2 \mathrm{H}, \mathrm{m}), 1.66(1 \mathrm{H}, \mathrm{m}), 1.90(1 \mathrm{H}, \mathrm{m}), 3.29(2 \mathrm{H}, \mathrm{m}), 3.45(1 \mathrm{H}, \mathrm{dd}, J=4.9,11.0 \mathrm{~Hz})$, $3.58(1 \mathrm{H}, \mathrm{dd}, J=4.9,11.0 \mathrm{~Hz}), 3.88(1 \mathrm{H}, \mathrm{m}), 4.49(2 \mathrm{H}, \mathrm{s}), 7.33(5 \mathrm{H}, \mathrm{m}) ;{ }^{13} \mathrm{C}-\mathrm{NMR}(100 \mathrm{MHz}) \delta-4.5$, $-4.4,17.7,18.1,25.8,29.6,38.2,66.6,70.8,73.0,76.1,127.4,127.5,128.3,138.5$. ESI-MS: calcd for $\mathrm{C}_{19} \mathrm{H}_{34} \mathrm{O}_{3} \mathrm{SiNa} 361.2175(\mathrm{M}+\mathrm{Na})^{+}$, found, $m / z$ 361.2168.

(R)-4-Benzyl-3-((4R,6R,E)-7-(benzyloxy)-6-methyl-4-(tert-butyldimethylsilyloxy)hept-2-enoyl)oxazolidin-2-one (15). To a solution of $14(4.39 \mathrm{~g}, 13 \mathrm{mmol})$ in $\mathrm{CH}_{2} \mathrm{Cl}_{2}(65 \mathrm{~mL})$ and DMSO $(65 \mathrm{~mL})$ were added $\mathrm{Et}_{3} \mathrm{~N}(5.4 \mathrm{~mL}, 39 \mathrm{mmol})$ and $\mathrm{SO}_{3}$-pyridine $(6.2 \mathrm{~g}, 39 \mathrm{mmol})$ complex at $0{ }^{\circ} \mathrm{C}$. After $2 \mathrm{~h}$, the reaction was quenched with saturated aqueous $\mathrm{NH}_{4} \mathrm{Cl}$, and the mixture was partitioned between $\mathrm{Et}_{2} \mathrm{O}$ and $\mathrm{H}_{2} \mathrm{O}$. The organic layer was dried $\left(\mathrm{Na}_{2} \mathrm{SO}_{4}\right)$, and concentrated in vacuo. The residue was purified by silica gel column chromatography (hexane-ethyl acetate 6:1) to give an aldehyde $(4.3 \mathrm{~g}, 99 \%)$ as a colorless oil.

To a suspension of $\mathrm{LiCl}(0.09 \mathrm{~g}, 2.2 \mathrm{mmol})$ in anhydrous $\mathrm{CH}_{3} \mathrm{CN}(8 \mathrm{~mL})$ were added $16(0.29 \mathrm{~g}$, $0.81 \mathrm{mmol})$, DIPEA $(0.3 \mathrm{~mL}, 1.65 \mathrm{mmol})$, and the aldehyde $(0.18 \mathrm{~g}, 0.55 \mathrm{mmol})$ at room temperature; the mixture was stirred at room temperature for overnight. The reaction was quenched with saturated aqueous $\mathrm{NH}_{4} \mathrm{Cl}$, and the mixture was partitioned between $\mathrm{Et}_{2} \mathrm{O}$ and $\mathrm{H}_{2} \mathrm{O}$. The organic layer was dried $\left(\mathrm{Na}_{2} \mathrm{SO}_{4}\right)$, and concentrated in vacuo. The residue was purified by silica gel column chromatography (hexane-ethyl acetate 6:1) to give 15 (0.33 g, quant.) as a colorless oil: $[\alpha]^{24}{ }_{\mathrm{D}}-23.1$ (c 1.02, $\left.\mathrm{CHCl}_{3}\right)$; IR (film) 1782, 1683, 1639, 1352, 1207, 1100, $836 \mathrm{~cm}^{-1} ;{ }^{1} \mathrm{H}-\mathrm{NMR}(400 \mathrm{MHz}) \delta 0.07$ (6H, s), 0.93 $(9 \mathrm{H}, \mathrm{s}), 0.99(3 \mathrm{H}, \mathrm{d}, J=6.8 \mathrm{~Hz}), 1.35(1 \mathrm{H}, \mathrm{ddd}, J=4.9,8.8,13.7 \mathrm{~Hz}), 1.75(1 \mathrm{H}, \mathrm{ddd}, J=4.9,8.8,13.7$ $\mathrm{Hz}), 2.02(1 \mathrm{H}, \mathrm{m}), 2.81(1 \mathrm{H}, \mathrm{dd}, J=9.8,13.7 \mathrm{~Hz}), 3.32(3 \mathrm{H}, \mathrm{m}), 4.19(2 \mathrm{H}, \mathrm{m}), 4.50(3 \mathrm{H}, \mathrm{m}), 4.73(1 \mathrm{H}$, ddd, $J=3.4,6.8,12.7 \mathrm{~Hz}), 7.37(12 \mathrm{H}, \mathrm{m}) ;{ }^{13} \mathrm{C}-\mathrm{NMR}(100 \mathrm{MHz}) \delta-5.0,-4.3,17.3,18.1,25.8,29.7$, $37.9,41.6,55.3,66.1,70.2,72.9,76.0,77.3,118.7,127.3,127.4,127.5,128.3,128.9,129.5,135.3$, 138.6, 153.2, 153.6, 165.0. ESI-MS: calcd for $\mathrm{C}_{31} \mathrm{H}_{43} \mathrm{NO}_{5} \mathrm{SiNa} 560.2808(\mathrm{M}+\mathrm{Na})^{+}$, found, $\mathrm{m} / z$ 560.2808 .

(R)-4-Benzyl-3-((2R,4R,6R)-7-(benzyloxy)-2,6-dimethyl-4-(tert-butyldimethylsilyloxy)heptanoyl)oxazol -idin-2-one (17). To a solution of $15(6.21 \mathrm{~g}, 11.6 \mathrm{mmol})$ in ethyl acetate $(120 \mathrm{~mL})$ was added $\mathrm{Rh}$ $\mathrm{Al}_{2} \mathrm{O}_{3}$ (cat.) at room temperature under hydrogen atmosphere; the mixture was stirred for $2 \mathrm{~h}$. The reaction mixture was filtered and concentrated in vacuo. The residue was purified by silica gel column chromatography (hexane-ethyl acetate $6: 1)$ to give an amide $(5.99 \mathrm{~g}, 96 \%)$ as a colorless oil: $[\alpha]^{24}{ }_{\mathrm{D}}$ -23.6 (c 0.99, $\mathrm{CHCl}_{3}$ ); IR (film) 1784, 1701, 1210, $835 \mathrm{~cm}^{-1} ;{ }^{1} \mathrm{H}-\mathrm{NMR}(400 \mathrm{MHz}$,) $\delta 0.07(6 \mathrm{H}, \mathrm{d}$, $J=4.9 \mathrm{~Hz}), 0.90(9 \mathrm{H}, \mathrm{s}), 0.97(3 \mathrm{H}, \mathrm{d}, J=6.5 \mathrm{~Hz}), 1.26(1 \mathrm{H}, \mathrm{ddd}, J=5.4,8.1,13.7 \mathrm{~Hz}), 1.62(1 \mathrm{H}, \mathrm{ddd}$, $J=5.4,7.2,13.7 \mathrm{~Hz}), 1.88(3 \mathrm{H}, \mathrm{m}), 2.76(1 \mathrm{H}, \mathrm{dd}, J=9.6,13.7 \mathrm{~Hz}), 2.92(1 \mathrm{H}, \mathrm{ddd}, J=5.4,9.6$, $17.3 \mathrm{~Hz}), 3.05(1 \mathrm{H}, \mathrm{ddd}, J=5.4,9.6,17.3 \mathrm{~Hz}), 3.31(3 \mathrm{H}, \mathrm{m}), 3.89(1 \mathrm{H}, \mathrm{tt}, J=5.4,11.7 \mathrm{~Hz}), 4.17(2 \mathrm{H}, \mathrm{m})$, $4.50(2 \mathrm{H}, \mathrm{s}), 4.66(1 \mathrm{H}, \mathrm{ddd}, J=3.4,7.2,13.0 \mathrm{~Hz}), 7.34(10 \mathrm{H}, \mathrm{m}) ;{ }^{13} \mathrm{C}-\mathrm{NMR}(100 \mathrm{MHz}) \delta-4.5$, $-4.4,17.6,18.0,25.9,29.8,31.5,31.7,37.9,41.3,55.1,66.1,69.2,72.8,76.1,127.4,127.5,128.2$, 128.3, 128.9, 129.4, 135.3, 153.4, 173.4. ESI-MS: calcd for $\mathrm{C}_{31} \mathrm{H}_{45} \mathrm{NO}_{5} \mathrm{SiNa} 562.2965(\mathrm{M}+\mathrm{Na})^{+}$, found, $m / z 562.2962$.

To a solution of LHMDS (47 mL, 1.0 M in THF, $47 \mathrm{mmol})$ in THF (100 mL) was added the amide $(5.07 \mathrm{~g}, 9.4 \mathrm{mmol})$ at $-40^{\circ} \mathrm{C}$. After being stirred at same temperature for $2 \mathrm{~h}, \mathrm{MeI}(12 \mathrm{~mL}, 0.19 \mathrm{~mol})$ was added and the resultant mixture stirred at $-20{ }^{\circ} \mathrm{C}$ for $0.5 \mathrm{~h}$. After the addition of saturated aqueous 
$\mathrm{NH}_{4} \mathrm{Cl}$, the mixture was extracted with ethyl acetate. The organic layer was dried $\left(\mathrm{Na}_{2} \mathrm{SO}_{4}\right)$, and concentrated in vacuo. The residue was purified by silica gel column chromatography (hexane-ethyl acetate 9:1) to give $17(4.03 \mathrm{~g}, 77 \%)$ as a colorless oil: $[\alpha]^{24}{ }_{\mathrm{D}}-41.5\left(c 1.00, \mathrm{CHCl}_{3}\right)$; IR (film) 1783, 1697, 1455, 1386, 1209, $836 \mathrm{~cm}^{-1}$; ${ }^{1} \mathrm{H}-\mathrm{NMR}(400 \mathrm{MHz}) \delta 0.05(6 \mathrm{H}, \mathrm{d}, J=14.6 \mathrm{~Hz}), 0.90(9 \mathrm{H}, \mathrm{s}), 1.02$ $(3 \mathrm{H}, \mathrm{d}, J=6.1 \mathrm{~Hz}), 1.32(4 \mathrm{H}, \mathrm{m}), 1.58(2 \mathrm{H}, \mathrm{m}), 1.98(1 \mathrm{H}, \mathrm{ddd}, J=6.7,13.2,19.7 \mathrm{~Hz}), 2.11(1 \mathrm{H}, \mathrm{m})$, $2.80(1 \mathrm{H}, \mathrm{dd}, J=10.1,13.2 \mathrm{~Hz}), 3.34(3 \mathrm{H}, \mathrm{m}), 3.84(2 \mathrm{H}, \mathrm{m}), 4.18(2 \mathrm{H}, \mathrm{m}), 4.55(2 \mathrm{H}, \mathrm{s}), 4.67(1 \mathrm{H}, \mathrm{m})$, $7.33(10 \mathrm{H}, \mathrm{m}) ;{ }^{13} \mathrm{C}-\mathrm{NMR}(100 \mathrm{MHz}) \delta-4.7,-4.3,17.9,18.0,18.6,25.8,29.9,34.3,37.9,40.7,41.6$, 55.3, 65.9, 68.7, 72.9, 76.0, 127.3, 127.5, 128.2, 128.9, 129.4, 135.3, 138.8, 152.8, 176.8. ESI-MS: calcd for $\mathrm{C}_{32} \mathrm{H}_{48} \mathrm{NO}_{5} \mathrm{Si} 554.3302(\mathrm{M}+\mathrm{H})^{+}$, found, $m / z$ 554.3292.

(4R,6R,8R)-9-(Benzyloxy)-4,8-dimethyl-6-(tert-butyldimethylsilyloxy)nonan-3-one (18). To a solution of 17 (4.7 g, $8.49 \mathrm{mmol})$ in THF-MeOH-H${ }_{2} \mathrm{O}(4: 4: 1,90 \mathrm{~mL})$ was added $\mathrm{LiBH}_{4}(0.82 \mathrm{~g}, 34 \mathrm{mmol})$ at $0{ }^{\circ} \mathrm{C}$; the mixture was stirred at room temperature for $1 \mathrm{~h}$. After the addition of saturated aqueous $\mathrm{NH}_{4} \mathrm{Cl}$, the mixture was extracted with $\mathrm{Et}_{2} \mathrm{O}$. The organic layer was dried $\left(\mathrm{Na}_{2} \mathrm{SO}_{4}\right)$, and concentrated in vacuo. The residue was purified by silica gel column chromatography (hexane-ethyl acetate $5: 1$ ) to give an alcohol $(3.02 \mathrm{~g}, 93 \%)$ as a yellow oil: $[\alpha]^{24}+9.1\left(c 1.00, \mathrm{CHCl}_{3}\right)$; IR (film) 1459, 1255, 1049, $835 \mathrm{~cm}^{-1}$; ${ }^{1} \mathrm{H}-\mathrm{NMR}(400 \mathrm{MHz}) \delta 0.08(6 \mathrm{H}, \mathrm{d}, J=3.6 \mathrm{~Hz}), 0.87(3 \mathrm{H}, \mathrm{d}, J=7.2 \mathrm{~Hz}), 0.90(9 \mathrm{H}, \mathrm{s}), 0.95$ $(3 \mathrm{H}, \mathrm{d}, J=7.2 \mathrm{~Hz}), 1.38(1 \mathrm{H}, \mathrm{ddd}, J=6.3,7.2,13.7 \mathrm{~Hz}), 1.55(4 \mathrm{H}, \mathrm{m}), 1.86(2 \mathrm{H}, \mathrm{m}), 3.26(2 \mathrm{H}, \mathrm{m})$, $3.33(1 \mathrm{H}, \mathrm{m}), 3.44(1 \mathrm{H}, \mathrm{m}), 3.98(1 \mathrm{H}, \mathrm{tt}, J=4.5,11.4 \mathrm{~Hz}), 4.49(2 \mathrm{H}, \mathrm{s}), 7.33(5 \mathrm{H}, \mathrm{m}) ;{ }^{13} \mathrm{C}-\mathrm{NMR}$ (100 MHz) $\delta-4.6,-4.4,17.8,18.0,18.3,25.8,30.0,31.8,40.6,42.6,69.3,73.0,76.2,127.4,127.5$, 128.3, 138.6. ESI-MS: calcd for $\mathrm{C}_{22} \mathrm{H}_{41} \mathrm{O}_{3} \mathrm{Si} 381.2825(\mathrm{M}+\mathrm{H})^{+}$, found, $\mathrm{m} / z$ 381.2821.

To a solution of the alcohol $(2.5 \mathrm{mg}, 6.6 \mu \mathrm{mol})$ in $\mathrm{CH}_{2} \mathrm{Cl}_{2}(0.05 \mathrm{~mL})$ and DMSO $(0.05 \mathrm{~mL})$ were added $\mathrm{Et}_{3} \mathrm{~N}(3 \mu \mathrm{L}, 19.7 \mu \mathrm{mol})$ and $\mathrm{SO}_{3}$-pyridine $(3 \mathrm{mg}, 19.7 \mu \mathrm{mol})$ complex at $0{ }^{\circ} \mathrm{C}$. After $1.5 \mathrm{~h}$, the reaction was quenched with saturated aqueous $\mathrm{NH}_{4} \mathrm{Cl}$, and the mixture was partitioned between $\mathrm{Et}_{2} \mathrm{O}$ and $\mathrm{H}_{2} \mathrm{O}$. The organic layer was dried $\left(\mathrm{Na}_{2} \mathrm{SO}_{4}\right)$, and concentrated in vacuo. The residue was purified by PLC (hexane-ethyl acetate 3:1) to give an aldehyde as a colorless oil.

To a solution of the aldehyde in THF $(0.1 \mathrm{~mL})$ was added $\operatorname{EtMgBr}(0.02 \mathrm{~mL}, 1.0 \mathrm{M}$ in THF, $19.7 \mu \mathrm{mol}$ ) at $0{ }^{\circ} \mathrm{C}$; the mixture was stirred at the same temperature for $15 \mathrm{~min}$. The reaction mixture was quenched with saturated aqueous $\mathrm{NH}_{4} \mathrm{Cl}$, and extracted with $\mathrm{CH}_{2} \mathrm{Cl}_{2}$. The organic layer was dried $\left(\mathrm{Na}_{2} \mathrm{SO}_{4}\right)$, and concentrated in vacuo. The residue was purified by PLC (hexane-ethyl acetate (5:1)) to give an alcohol as a colorless oil.

To a solution of the alcohol in $\mathrm{CH}_{2} \mathrm{Cl}_{2}(0.05 \mathrm{~mL})$ and DMSO $(0.05 \mathrm{~mL})$ were added $\mathrm{Et}_{3} \mathrm{~N}(3 \mu \mathrm{L}$, $19.7 \mu \mathrm{mol}$ ) and $\mathrm{SO}_{3}$-pyridine $\left(3 \mathrm{mg}, 19.7 \mu \mathrm{mol}\right.$ ) complex at $0{ }^{\circ} \mathrm{C}$. After $4 \mathrm{~h}$, the reaction was quenched with saturated aqueous $\mathrm{NH}_{4} \mathrm{Cl}$, and the mixture was partitioned between $\mathrm{Et}_{2} \mathrm{O}$ and $\mathrm{H}_{2} \mathrm{O}$. The organic layer was dried $\left(\mathrm{Na}_{2} \mathrm{SO}_{4}\right)$, and concentrated in vacuo. The residue was purified by PLC (hexane-ethyl acetate (5:1) to give 18 (2.5 mg 89\% in 3 steps) as a colorless oil: $[\alpha]^{24}+1.1\left(c 0.98, \mathrm{CHCl}_{3}\right)$; IR (film) 1714, 1459, 1255, 1099, $835 \mathrm{~cm}^{-1}$; ${ }^{1} \mathrm{H}-\mathrm{NMR}(400 \mathrm{MHz}) \delta 0.02(6 \mathrm{H}, \mathrm{d}, J=6.7 \mathrm{~Hz}), 0.87(9 \mathrm{H}, \mathrm{s})$, $0.95(3 \mathrm{H}, \mathrm{d}, J=7.2 \mathrm{~Hz}), 1.05(6 \mathrm{H}, \mathrm{m}), 1.22(1 \mathrm{H}, \mathrm{m}), 1.35(1 \mathrm{H}, \mathrm{m}), 1.57(1 \mathrm{H}, \mathrm{m}), 1.93(1 \mathrm{H}, \mathrm{m}), 2.46$ $(2 \mathrm{H}, \mathrm{m}), 2.66(\mathrm{qt}, 1 \mathrm{H}, J=7.2,13.7 \mathrm{~Hz}), 3.26(1 \mathrm{H}, \mathrm{dd}, J=6.1,8.8 \mathrm{~Hz}), 3.33(1 \mathrm{H}, \mathrm{dd}, J=6.1,8.8 \mathrm{~Hz})$, $3.75(1 \mathrm{H}, \mathrm{tt}, J=5.8,12.1 \mathrm{~Hz}), 4.50(2 \mathrm{H}, \mathrm{s}), 7.33(5 \mathrm{H}, \mathrm{m}) ;{ }^{13} \mathrm{C}-\mathrm{NMR}(100 \mathrm{MHz}) \delta-4.34,-4.30,7.8$, 17.5, 17.7, 18.1, 25.9, 29.8, 34.2, 40.6, 41.4, 42.3, 68.8, 75.9, 127.4, 127.5, 128.3, 138.8, 214.7. ESI-MS: calcd for $\mathrm{C}_{24} \mathrm{H}_{43} \mathrm{O}_{3} \mathrm{Si} 407.2981(\mathrm{M}+\mathrm{H})^{+}$, found, $\mathrm{m} / z$ 407.2982. 
((2R,4S,6R)-1-(Benzyloxy)-2,6-dimethyl-7-methylenenonan-4-yloxy)(tert-butyl)dimethylsilane (19). To a solution of ethyl ketone $18(60.0 \mathrm{mg}, 0.12 \mathrm{mmol})$ in THF (1 mL) was added (trimethylsilylmethyl) lithium $(0.5 \mathrm{~mL}, 1.0 \mathrm{M}$ in pentane, $0.5 \mathrm{mmol})$ at $-78{ }^{\circ} \mathrm{C}$; the mixture was stirred at the same temperature for $20 \mathrm{~min}$. The reaction mixture was quenched with saturated aqueous $\mathrm{NH}_{4} \mathrm{Cl}$, and extracted with ethyl acetate. The organic layer was dried $\left(\mathrm{Na}_{2} \mathrm{SO}_{4}\right)$, and concentrated in vacuo. The residue was purified by PLC (hexane-ethyl acetate 9:1) to give an alcohol as a colorless oil.

To a solution of the alcohol in THF $(2 \mathrm{~mL})$ was added $\mathrm{NaH}(60 \%$ dispersion in mineral oil, $50 \mathrm{mg}$, $0.1 \mathrm{mmol}$ ) at room temperature; the mixture was stirred at reflux temperature overnight. The reaction was quenched with saturated aqueous $\mathrm{NH}_{4} \mathrm{Cl}$, and the mixture was extracted with ethyl acetate. The organic layer was dried $\left(\mathrm{Na}_{2} \mathrm{SO}_{4}\right)$ and concentrated in vacuo. The residue was purified by PLC (hexane-ethyl acetate 9:1) to give 19 as a colorless oil (48 mg, 86\% in 2 steps): $[\alpha]^{24}{ }_{\mathrm{D}}+17.8(c 1.01$, $\mathrm{CHCl}_{3}$ ); IR (film) 2958, 1642, 1460, 1254, 1097, $835 \mathrm{~cm}^{-1} ;{ }^{1} \mathrm{H}-\mathrm{NMR}(400 \mathrm{MHz}) \delta 0.05(6 \mathrm{H}, \mathrm{s}), 0.89$ $(9 \mathrm{H}, \mathrm{s}), 0.95(3 \mathrm{H}, \mathrm{d}, J=6.5 \mathrm{~Hz}), 1.02(6 \mathrm{H}, \mathrm{m}), 1.24(1 \mathrm{H}, \mathrm{m}), 1.46(2 \mathrm{H}, \mathrm{m}), 1.61(1 \mathrm{H}, \mathrm{m}), 1.99$ $(3 \mathrm{H}, \mathrm{m}), 2.19(1 \mathrm{H}, \mathrm{m}), 3.23(1 \mathrm{H}, \mathrm{dd}, J=6.5,9.1 \mathrm{~Hz}), 3.34(1 \mathrm{H}, \mathrm{dd}, J=6.5,9.1 \mathrm{~Hz}), 3.77(1 \mathrm{H}, \mathrm{m}), 4.50$ $(2 \mathrm{H}, \mathrm{s}), 4.72(2 \mathrm{H}, \mathrm{dd}, J=1.5,11.9 \mathrm{~Hz}), 7.33(5 \mathrm{H}, \mathrm{m}) ;{ }^{13} \mathrm{C}-\mathrm{NMR}(100 \mathrm{MHz}) \delta-4.2,-4.1,12.4,17.4$, 18.1, 20.3, 26.0, 26.2, 29.7, 36.8, 41.3, 44.2, 69.0, 72.8, 76.3, 106.4, 127.4, 127.5, 128.3, 138.8, 156.3. ESI-MS: calcd for $\mathrm{C}_{25} \mathrm{H}_{45} \mathrm{O}_{2} \mathrm{Si} 405.3189(\mathrm{M}+\mathrm{H})^{+}$, found, $m / z$ 405.3181.

(4R,6S,8R)-6-(tert-Butyldimethylsilyloxy)-4,8-dimethyl-9-methyleneundecan-3-one (segment B, 3). To a solution of lithium $(12.4 \mathrm{mg}, 1.9 \mathrm{mmol})$ in liquid $\mathrm{NH}_{3}(10 \mathrm{~mL})$ was added $19(46.4 \mathrm{mg}$, $0.11 \mathrm{mmol})$ in dry THF $(3 \mathrm{~mL})$ at $-78{ }^{\circ} \mathrm{C}$. The reaction mixture was stirred for $15 \mathrm{~min}$ at the same temperature; and quenched with solid $\mathrm{NH}_{4} \mathrm{Cl}$. The mixture was extracted with ethyl acetate, and the organic layer was dried $\left(\mathrm{Na}_{2} \mathrm{SO}_{4}\right)$, and concentrated in vacuo. The residue was purified by silica gel column chromatography (hexane-ethyl acetate 5:1) to give an alcohol (35.6 $\mathrm{mg}, 99 \%)$ as a colorless oil: $[\alpha]_{\mathrm{D}}^{24}+36.4\left(c 0.98, \mathrm{CHCl}_{3}\right)$; IR (film) 3346, 2959, 1643, 1461, 1254, 1046, $835 \mathrm{~cm}^{-1}$; ${ }^{1} \mathrm{H}-\mathrm{NMR}$ $(400 \mathrm{MHz}) \delta 0.06(6 \mathrm{H}, \mathrm{d}, J=1.6 \mathrm{~Hz}), 0.89(9 \mathrm{H}, \mathrm{s}), 0.93(3 \mathrm{H}, \mathrm{d}, J=6.3 \mathrm{~Hz}), 1.02(6 \mathrm{H}, \mathrm{m}), 1.27(1 \mathrm{H}$, ddd, $J=3.7,8.5,13.9 \mathrm{~Hz}), 1.46(2 \mathrm{H}, \mathrm{m}), 1.59(1 \mathrm{H}, \mathrm{m}), 1.81(1 \mathrm{H}, \mathrm{ttd}, J=2.2,6.3,13.0 \mathrm{~Hz}), 2.00(2 \mathrm{H}$, m), $2.16(1 \mathrm{H}, \mathrm{qt}, J=6.3,7.0 \mathrm{~Hz}), 3.45(2 \mathrm{H}, \mathrm{dd}, J=4.5,6.3 \mathrm{~Hz}), 3.76(1 \mathrm{H}, \mathrm{m}), 4.72(2 \mathrm{H}, \mathrm{ddd}, J=1.6$, 2.9, $11.9 \mathrm{~Hz}) ;{ }^{13} \mathrm{C}-\mathrm{NMR}(100 \mathrm{MHz}) \delta-4.2,-4.0,12.4,17.0,18.1,20.1,25.8,25.9,26.3,32.3$, 36.9, 40.8, 44.4, 68.8, 69.3, 106.4, 156.3. ESI-MS: calcd for $\mathrm{C}_{18} \mathrm{H}_{39} \mathrm{O}_{2} \mathrm{Si} 315.2719(\mathrm{M}+\mathrm{H})^{+}$, found, $\mathrm{m} / \mathrm{z} 315.2717$.

To a solution of the alcohol $(0.35 \mathrm{~g}, 1.10 \mathrm{mmol})$ in $\mathrm{CH}_{2} \mathrm{Cl}_{2}(6 \mathrm{~mL})$ and DMSO $(6 \mathrm{~mL})$ were added $\mathrm{Et}_{3} \mathrm{~N}(0.5 \mathrm{~mL}, 3.29 \mathrm{mmol})$ and $\mathrm{SO}_{3}$-pyridine $(0.52 \mathrm{~g}, 3.29 \mathrm{mmol})$ complex at $0{ }^{\circ} \mathrm{C}$. After $1 \mathrm{~h}$, the reaction was quenched with saturated aqueous $\mathrm{NH}_{4} \mathrm{Cl}$, and the mixture was partitioned between $\mathrm{Et}_{2} \mathrm{O}$ and $\mathrm{H}_{2} \mathrm{O}$. The organic layer was dried $\left(\mathrm{Na}_{2} \mathrm{SO}_{4}\right)$, and concentrated in vacuo. The residue was purified by silica gel column chromatography (hexane-ethyl acetate $7: 1$ ) to give an aldehyde as a colorless oil.

To a solution of the aldehyde in THF $(10 \mathrm{~mL})$ was added EtMgBr $(3 \mathrm{~mL}, 1.0 \mathrm{M}$ in THF, 2.95 $\mathrm{mmol}$ ) at $0{ }^{\circ} \mathrm{C}$; the mixture was stirred at the same temperature for $30 \mathrm{~min}$. The reaction was quenched with saturated aqueous $\mathrm{NH}_{4} \mathrm{Cl}$, and the mixture was extracted with $\mathrm{CH}_{2} \mathrm{Cl}_{2}$. The organic layer was dried $\left(\mathrm{Na}_{2} \mathrm{SO}_{4}\right)$, and concentrated in vacuo. The residue was purified by silica gel column chromatography (hexane-ethyl acetate (9:1)) to give an alcohol as a colorless oil. 
To a solution of the alcohol in $\mathrm{CH}_{2} \mathrm{Cl}_{2}(4 \mathrm{~mL})$ and DMSO $(4 \mathrm{~mL})$ were added $\mathrm{Et}_{3} \mathrm{~N}(0.32 \mathrm{~mL}$, $2.34 \mathrm{mmol})$ and $\mathrm{SO}_{3}$-pyridine $(0.4 \mathrm{~g}, 2.34 \mathrm{mmol})$ complex at $0{ }^{\circ} \mathrm{C}$. After $40 \mathrm{~min}$, the reaction was quenched with saturated aqueous $\mathrm{NH}_{4} \mathrm{Cl}$, and the mixture was partitioned between $\mathrm{Et}_{2} \mathrm{O}$ and $\mathrm{H}_{2} \mathrm{O}$. The organic layer was dried $\left(\mathrm{Na}_{2} \mathrm{SO}_{4}\right)$, and concentrated in vacuo. The residue was purified by silica gel column chromatography (hexane-ethyl acetate $11: 1)$ to give segment $\mathbf{B}(0.22 \mathrm{~g} 60 \%$ in 3 steps $)$ as a colorless oil.: $[\alpha]^{24}+11.7\left(c 0.99, \mathrm{CHCl}_{3}\right.$ ); IR (film) 2960, 1716, 1643, 1461, 1255, 1101, $835 \mathrm{~cm}^{-1}$; ${ }^{1} \mathrm{H}-\mathrm{NMR}(400 \mathrm{MHz}) \delta 0.06(6 \mathrm{H}, \mathrm{d}, J=3.8 \mathrm{~Hz}), 0.89(9 \mathrm{H}, \mathrm{s}), 1.02(12 \mathrm{H}, \mathrm{m}), 1.38(2 \mathrm{H}, \mathrm{m}), 1.55(1 \mathrm{H}$, ddd, $J=6.7,7.0,13.5 \mathrm{~Hz}), 1.74(1 \mathrm{H}, \mathrm{ddd}, J=5.2,7.0,13.5 \mathrm{~Hz}), 1.97(2 \mathrm{H}, \mathrm{m}), 2.16(1 \mathrm{H}, \mathrm{dd}, J=7.0$, $14.0 \mathrm{~Hz}), 2.47(2 \mathrm{H}, \mathrm{q}, J=7.0 \mathrm{~Hz}), 2.73(1 \mathrm{H}, \mathrm{qt}, J=7.0,14.0 \mathrm{~Hz}), 3.66(1 \mathrm{H}, \mathrm{m}), 4.70(2 \mathrm{H}, \mathrm{m})$; ${ }^{13} \mathrm{C}$ - NMR (100 MHz) $\delta-4.3,-4.1,7.9,12.3,16.4,18.1,20.3,25.9,26.2,34.2,36.8,40.1,41.8$, 44.0, 68.7, 77.3, 106.6, 156.0, 215.2. ESI-MS: calcd for $\mathrm{C}_{20} \mathrm{H}_{39} \mathrm{O}_{2} \mathrm{Si} 339.2719(\mathrm{M}+\mathrm{H})^{+}$, found, $\mathrm{m} / \mathrm{z}$ 339.2689 .

\section{Conclusions}

In conclusion, this study reports the efficient synthesis of promising segments $\mathbf{2}$ and $\mathbf{3}$ for the construction of amphidinolide Q (1). Both routes provided good yields and availability for analog synthesis.

\section{Acknowledgement}

This work was financially supported by High-Tech Research Center Project for Private Universities Matching Fund (2006-2011) and by The Science Research Promotion Fund from the Promotion and Mutual Aid Corporation for Private Schools of Japan from MEXT.

\section{References}

1. Kobayashi, J.; Takahashi, M.; Ishibashi, M. Amphidinolide Q, a novel 12-membered macrolide from the cultured marine dinoflagellate Amphidinium sp. Tetrahedron Lett. 1996, 37, 1449-1450.

2. Takahashi, Y.; Kubota, T.; Fukushi, E.; Kawabata, J.; Kobayashi, J. Absolute stereochemistry of amphidinolide Q. Org. Lett. 2008, 10, 3709-3711.

3. Hangyou, M.; Ishiyama, H.; Takahashi, Y.; Kobayashi, J. Total synthesis of amphidinolide Q. Org. Lett. 2009, 11, 5046-5049.

4. Fürstner, A.; Kattnig, E.; Lepage, O. Total syntheses of amphidinolide X and Y. J. Am. Chem. Soc. 2006, 128, 9194-9204.

5. Radha Krishna, P.; Narsingam, M. Studies directed towards the stereoselective total synthesis of ilexlactone via a tandem ring-closing enyne metathesis protocol. Tetrahedron Lett. 2007, 48, 8721-8724.

6. Hollowood, C.J.; Yamanoi, S.; Ley, S.V. Use of $\pi$-allyltricarbonyliron lactone complexes in the synthesis of taurospongin A: a potent inhibitor of DNA polymerase $\beta$ and HIV reverse transcriptase. Org. Biomol. Chem. 2003, 1, 1664-1675. 
7. Abushanab, E.; Vemishetti, P.; Leiby, R.W.; Singh, H.K.; Mikkilineni, A.B.; Wu, D.C.J.; Saibaba, R.; Raymond, P.P. The chemistry of L-ascorbic and D-isoascorbic acids. 1. The preparation of chiral butanetriol and -tetrols. J. Org. Chem. 1988, 53, 2598-2602.

8. Dias, L.C.; Melgar, G.Z.; Jardim, L.S.A. A short approach to the bicycle [4.3.0] nonane fragment of stawamycin. Tetrahedron Lett. 2005, 46, 4427-4431.

9. Choi, H.G.; Son, J.B.; Park, D.; Ham, Y.J.; Hah, J.; Sim, T. An efficient and enantioselective total synthesis of naturally occurring L-783277. Tetrahedron Lett. 2010, 51, 4942-4946.

10. Evans, D.A.; Dart, M.J.; Duffy, J.L.; Riegar, D.L. Double stereodifferentiating aldol reactions. The documentation of "partially matched" aldol bond constructions in the assemblage of polypropionate systems. J. Am. Chem. Soc. 1995, 117, 9073-9074.

11. At least two diastereomers were observed. Detailed structural elucidations are under way.

12. Experimental procedure and spectroscopic data will be reported elsewhere.

Sample Availability: Available from the authors.

(C) 2011 by the authors; licensee MDPI, Basel, Switzerland. This article is an open access article distributed under the terms and conditions of the Creative Commons Attribution license (http://creativecommons.org/licenses/by/3.0/). 